Universidad de Lima

Facultad de Comunicación

Carrera de Psicología

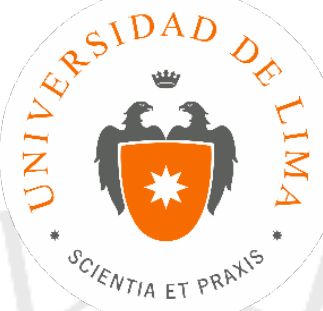

\title{
LA MIGRACIÓN DEL CAMPO A LA CIUDAD Y LA AMPLITUD DEL VOCABULARIO DE LOS NIÑOS PERUANOS A LOS 8 AÑOS DE EDAD
}

Tesis para optar el título profesional de Licenciado en Psicología

\author{
María Cristina Vásquez Bendezú \\ Código 20091187 \\ Asesor \\ Luis Miguel Escurra Mayaute
}

Lima - Perú

Noviembre del 2016 


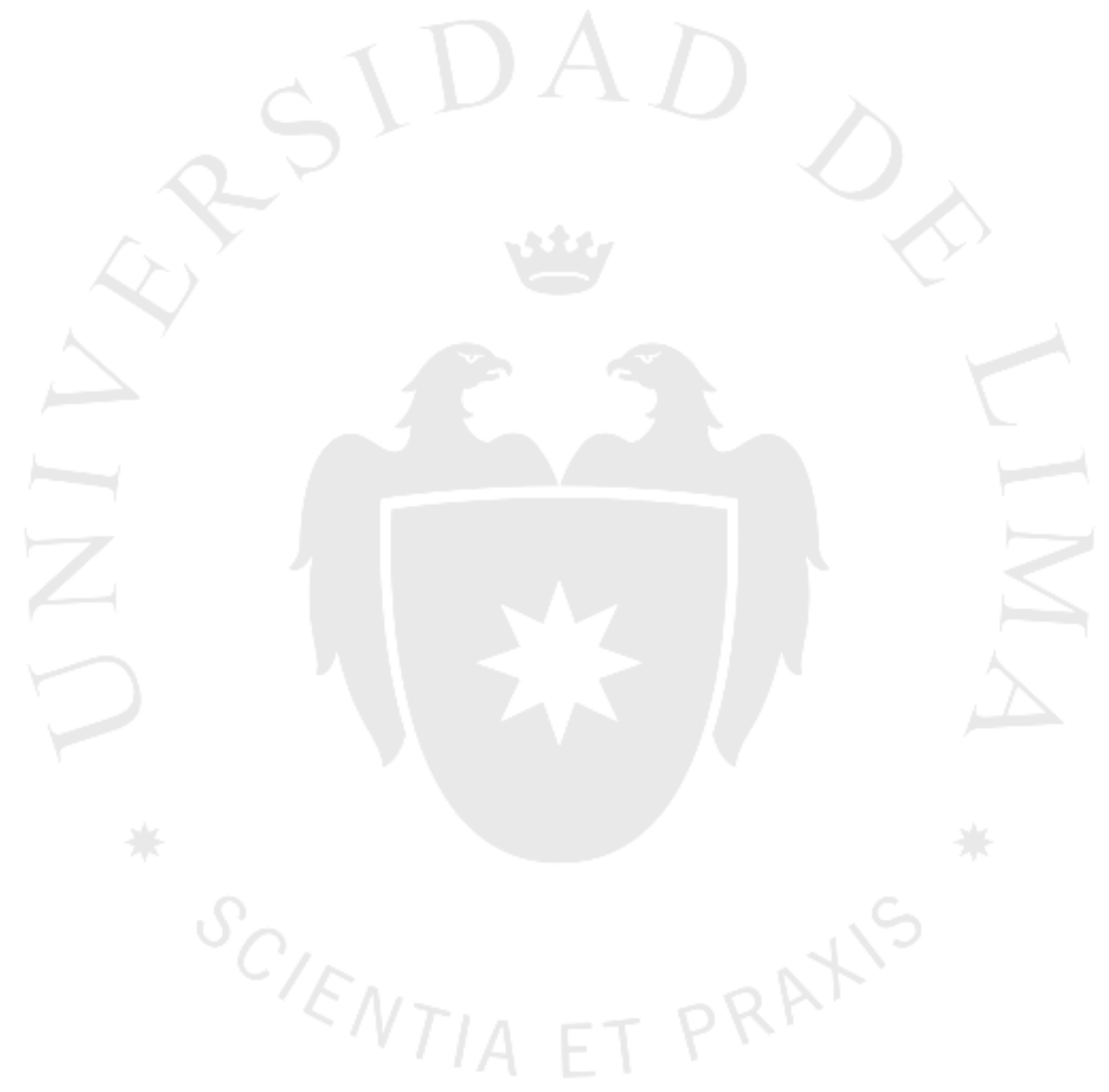


LA MIGRACIÓN DEL CAMPO A LA CIUDAD Y LA AMPLITUD DEL VOCABULARIO DE LOS NIÑOS PERUANOS A LOS 8 AÑOS DE EDAD 


\section{TABLA DE CONTENIDO}

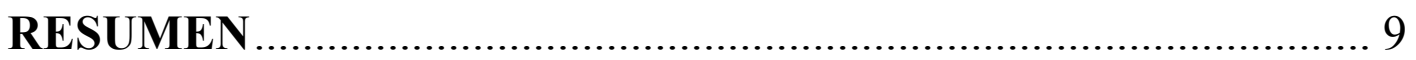

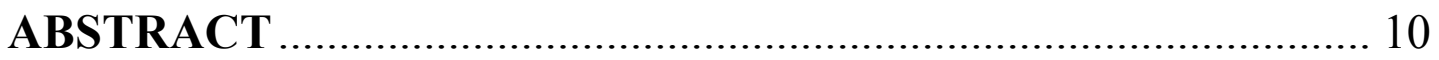

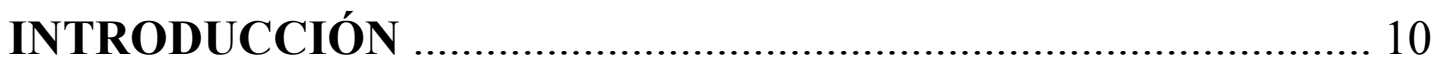

CAPÍTULO I: PLANTEAMIENTO DEL PROBLEMA.................. 12

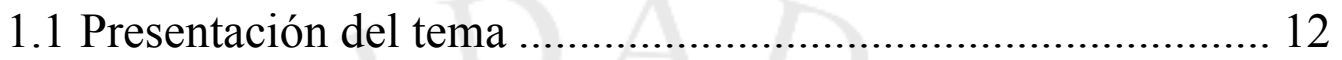

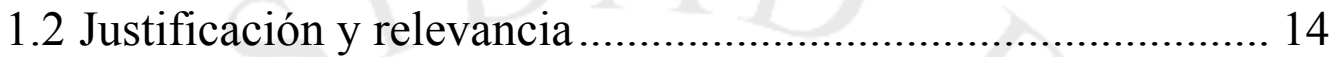

CAPÍTULO II: MARCO TEÓRICO .................................................. 17

2.1 Desarrollo del vocabulario: definiciones .................................. 17

$2.2 \mathrm{El}$ desarrollo del vocabulario a lo largo de la niñez .................. 18

2.3 Factores asociados al desarrollo del vocabulario .................... 20

$2.4 \mathrm{El} \mathrm{rol} \mathrm{de} \mathrm{la} \mathrm{migración} \mathrm{como} \mathrm{contexto} \mathrm{de} \mathrm{desarrollo} \mathrm{.................} 24$

2.5 Importancia del desarrollo del vocabulario en los procesos

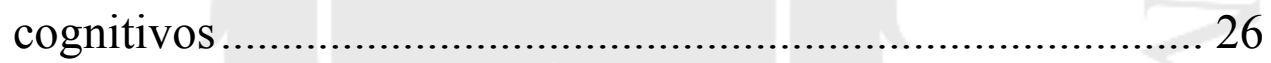

\section{CAPÍTULO III: OBJETIVOS, HIPÓTESIS Y DEFINICIÓN DE}

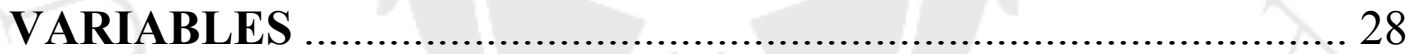

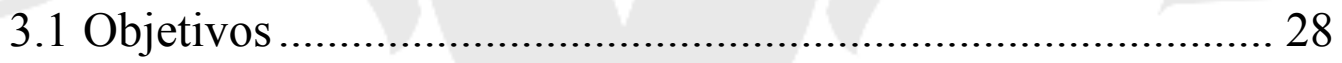

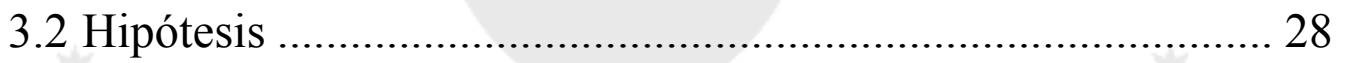

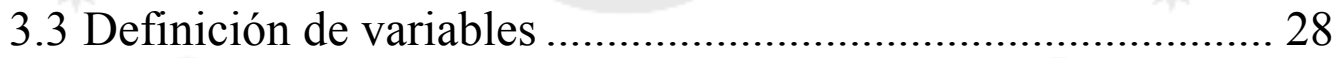

3.3.1. Variable dependiente..................................................... 29

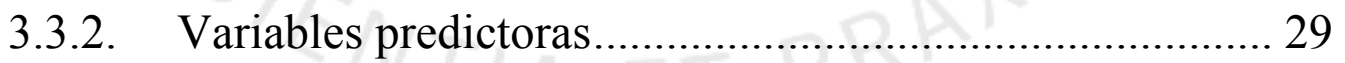

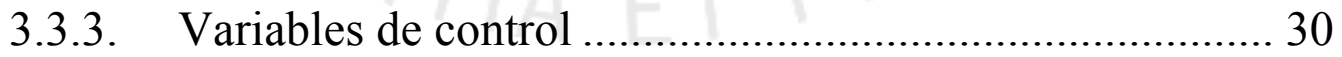

CAPÍTULO IV: METODOLOGÍA …............................................. 35

4.1 Tipo y diseño de investigación ............................................... 35

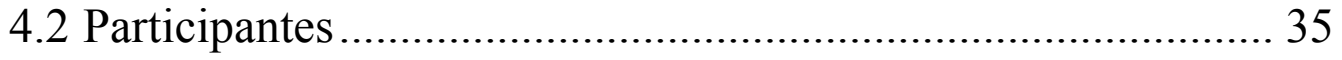

4.3 Técnicas de recolección de información.................................... 41

4.4 Procedimiento de recolección de datos.................................... 42 
CAPÍTULO V: RESULTADOS .................................................... 44

5.1 Estrategias de análisis de datos ................................................ 44

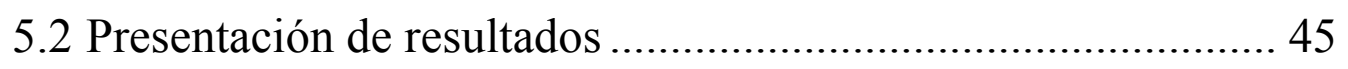

CAPÍTULO VI: DISCUSIÓN ......................................................... 53

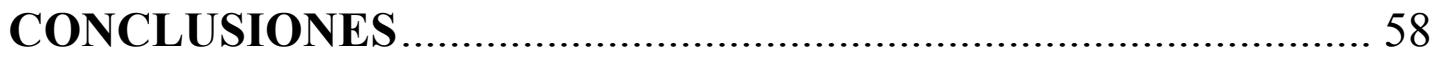

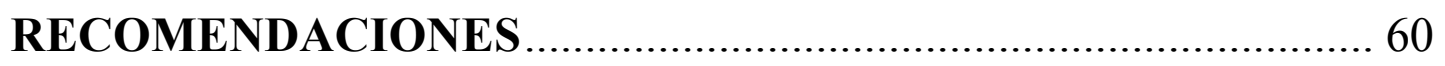

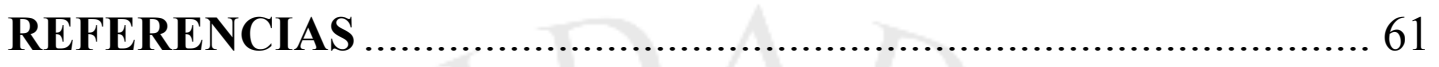




\section{ÍNDICE DE TABLAS}

Tabla 4.1. Distribución de frecuencias de la muestra para según momento

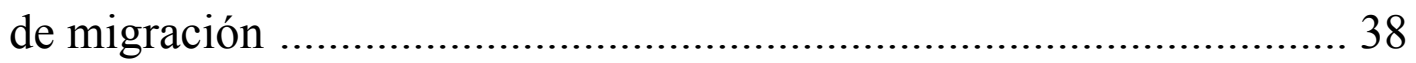

Tabla 4.2. Características demográficas de la muestra (variables dicotómicas)

Tabla 4.3. Características demográficas de la muestra (variables

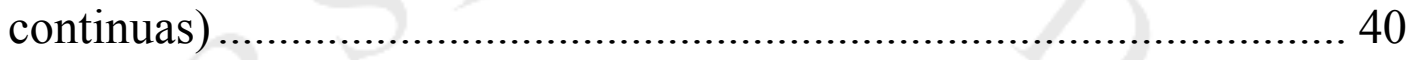

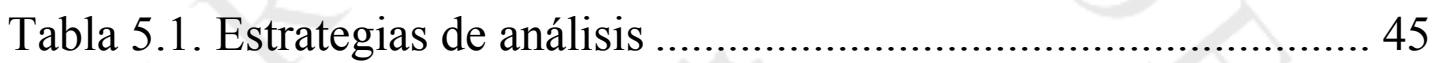

Tabla 5.2. Test de normalidad de asimetría y curtosis (Test de D’Agostino) 46

Tabla 5.3. Descripción de puntajes rasch para el TVIP según momento de

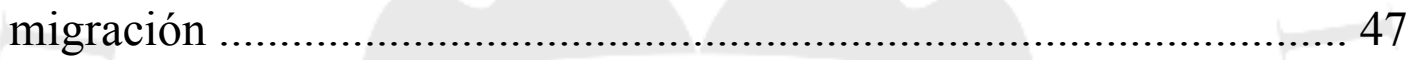

Tabla 5.4. Análisis de varianza Kruskal-Wallis...................................... 48

Tabla 5.5. Matriz de correlaciones entre las variables ........................... 49

Tabla 5.6. Variables predictoras del desarrollo del vocabulario

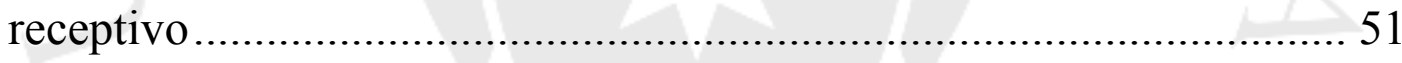

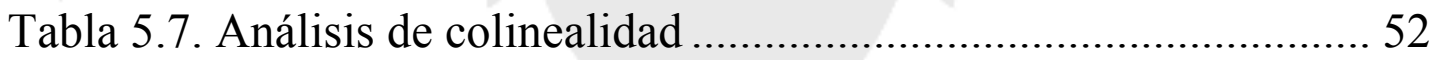




\section{ÍNDICE DE FIGURAS}

Figura 5.1. Distribución de puntajes rasch para el TVIP (desarrollo de vocabulario receptivo). 46 


\section{ÍNDICE DE ANEXOS}

Anexo 1: Variables predictoras del desarrollo del vocabulario y teoría ecológica 67

Anexo 2: Instrumento 1 - Hoja de Respuestas del TVIP 68

Anexo 3: Instrumento 2 - Preguntas del "Cuestionario del Hogar" (del Estudio Niños del Milenio) correspondientes a las variables de la presente investigación 70

Anexo 4: Licencia para el uso de datos del Estudio Niños del Milenio 75 


\section{RESUMEN}

La presente investigación busca identificar la influencia que tiene migrar a una ciudad, sobre el desarrollo lingüístico a los 8 años de edad de niños que nacieron en zonas rurales del Perú. Los participantes pertenecen a la muestra de un estudio longitudinal que permite recoger datos de su desarrollo desde que tenían alrededor de 6 meses de edad. Con dicha información, se realiza una regresión lineal múltiple que permite identificar los factores asociados a la amplitud del vocabulario. Se encuentra que la migración a zonas urbanas es un predictor estadísticamente significativo de una mayor amplitud en el vocabulario, medido por el Test de Vocabulario en Imágenes Peabody. De manera específica, los resultados indican que los niños que migraron antes de los 5 años de edad tienen más probabilidades de mejorar su vocabulario frente a aquellos que migraron después de los 5 años de edad. Los niños que permanecieron en zonas rurales obtuvieron los puntajes más bajos en amplitud del vocabulario. Respecto a las otras variables individuales y contextuales analizadas, los hallazgos coinciden con experiencias previas en las que se han encontrado factores similares asociados al desarrollo del vocabulario. Sin embargo, la migración rural-urbana como predictora de la amplitud en el vocabulario es una variable que no cuenta con evidencias previas en el Perú, por lo que este estudio permite entender, en el marco de la teoría ecológica de Bronfenbrenner (1987), la influencia tan importante que tienen los factores del contexto sobre el desarrollo del niño, para así poder desarrollar iniciativas que se enfoquen en la atención a los niños migrantes así como en la ruralidad como contexto que debe empoderarse para poder brindar mejores oportunidades a los niños peruanos.

Palabras clave: vocabulario, migración, rural, desarrollo, niñez, Perú 


\begin{abstract}
This study aims to identify if migrating to cities influences linguistic development of eight-year-olds born in Peruvian rural areas. Participants of the study belong to a longitudinal sample, which provides information on their development since they were 6 months old. A linear multiple regression is performed with this information to identify related factors to vocabulary development. It was found that migration to urban areas is a significant predictor of a greater receptive vocabulary, measured by the Peabody Picture Vocabulary Test. Specifically, results show that children migrating to cities before age 5 are more likely to have greater vocabulary at age 8 , than those who migrated after age 5 . The children who remained living in rural areas obtained the lowest vocabulary scores. Regarding individual and contextual variables here studied, findings are similar to those from previous studies about vocabulary development. Rural-urban migration as predictor of vocabulary amplitude is a variable with no previous evidence in Peru, which is why this study provides more information for understanding the importance of contextual factors in child development, taking into consideration Bronfenbrenner's ecological theory (1987). Therefore, it is expected that results from this study might help in the development of projects that focus on migrating children as well as on rural areas as a context that should be empowered to provide better opportunities for Peruvian children.
\end{abstract}

Key words: vocabulary, migration, rural, development, childhood, Peru 


\section{INTRODUCCIÓN}

La presente investigación busca identificar el rol predictor de la migración del campo a la ciudad sobre la amplitud del vocabulario de niños peruanos de 8 años de edad. Para tener información más precisa respecto a esta predicción, se toman en cuenta también otros posibles factores asociados que puedan influir sobre el desarrollo del vocabulario.

En el primer capítulo se plantea el problema identificado junto con la justificación del estudio, que motivan el desarrollo de esta investigación. Se resalta la importancia del vocabulario como uno de los ejes para el desarrollo cognitivo y académico de los niños peruanos. Asimismo, se presenta la relevancia de estudiar este tema en el marco de la migración entre zonas rurales y urbanas.

En el Capítulo II se desarrolla el Marco Teórico, en el cual se explica cómo se desarrolla el vocabulario desde los primeros meses de vida hasta la niñez. También se presentan las teorías e investigaciones que identifican los factores individuales, sociales y contextuales que influyen sobre la amplitud del vocabulario. A partir de ello, se describe el fenómeno de migración como uno de aquellos actores que podría repercutir en el desarrollo lingüístico. Finalmente, se sustenta teórica y empíricamente la importancia del vocabulario en el desarrollo cognitivo de los niños.

Los objetivos, hipótesis y variables son presentados en el Capítulo III. En este se definen, de forma tanto teórica como operacional, las variables dependientes, predictoras y de control, utilizadas en el estudio. Luego, en el Capítulo IV, se explica la Metodología que se utilizó para cumplir los objetivos de la investigación. Se señala el tipo y diseño de investigación, la descripción de los participantes y las técnicas y procedimientos que se emplearon para recolectar la información.

En el quinto capítulo se encontrarán los análisis necesarios para responder a la pregunta de investigación junto con sus resultados. En el capítulo siguiente, el sexto, se discuten los hallazgos y se interpretarán tomando como referencia los estudios presentados previamente.

Finalmente, en el Capítulo VII y VIII se enumeran las conclusiones y recomendaciones del estudio. Posteriormente, se encontrarán los Anexos, que contienen los instrumentos utilizados para recoger la información así como la licencia para el uso de los datos. 


\section{CAPÍTULO I: PLANTEAMIENTO DEL PROBLEMA}

\subsection{Presentación del tema}

Cada año se publican las distintas cifras que intentan retratar el panorama educativo del Perú, reportando sus mejoras sin poder evitar los bajos niveles de rendimiento académico presentados por los escolares peruanos. A nivel internacional, las calificaciones de los estudiantes de nuestro país se encuentran muy por debajo de lo que se espera para su edad en Matemática, Lectura y Ciencias. En las tres áreas mencionadas ellos ocupan el último lugar en el ranking de PISA 2012, que compara a 66 países (Ministerio de Educación [MINEDU], 2013), y más de la mitad de los estudiantes peruanos evaluados por TERCE se encuentran en los dos niveles inferiores de desempeño respecto a Comprensión Lectora (UNESCO, 2014). De igual manera a nivel nacional, en la Evaluación Censal de Estudiantes (ECE) se evidencia que los niños que asisten al segundo grado de primaria tienen un largo camino por recorrer para alcanzar los estándares de comprensión lectora y habilidades matemáticas que correspondan con su grado escolar, pues no alcanza el nivel satisfactorio siquiera la mitad de la población (49,8\% en Comprensión lectora y 26,6\% en Matemática) (MINEDU, 2016).

En los últimos resultados de la ECE, correspondientes al año 2015, se nota una mejora significativa de 6,3\% para el caso de Comprensión Lectora y 0,7\% para Matemática en comparación al año anterior (MINEDU, 2016); una tendencia similar se repite en las evaluaciones internacionales (MINEDU, 2013). Si bien se puede decir que en las distintas edades o grados evaluados los resultados están mejorando, aún no se alcanzan indicadores satisfactores. Por ello, es necesario identificar los distintos factores que son fundamentales para la mejora del rendimiento académico, particularmente el de comprensión lectora dado que a partir de este se desarrollan otros conocimientos necesarios tanto académica como socialmente (Flatts et al., 2016; Reátegui, 2008). Entendiendo que el proceso lector implica una práctica social en la que se integran procesos lingüísticos -como el conocimiento léxico- y factores psicológicos -como prácticas socioculturales-, resulta necesario desarrollar estudios e iniciativas de mejora que se enfoquen tanto en el desarrollo lingüístico como en el contexto psicosocial (Flatts et al., 2016). 
La adquisición del lenguaje es un proceso que se da paulatinamente en los niños desde sus primeros años de edad y que será fundamental durante su crecimiento para desarrollar habilidades cognitivas, entre ellas la comprensión lectora (Santrock, 2007). En el proceso lector juega un rol protagónico la adquisición del vocabulario, pues tomándola como base se podrá llevar a cabo el procesamiento semántico, una de las piezas claves para comprender lo que se lee (Núñez Delgado, 2013). A su vez, el hábito de lectura permite obtener buenos desempeños académicos en diversas asignaturas escolares, no solo en las relacionadas a letras (Dezcallar, Clariana, Cladelles, Badia y Gotzens, 2014). Además de la importancia en el rendimiento cognitivo y académico, el desarrollo del vocabulario surge como un mecanismo de adaptación para la socialización con el mundo que rodea al niño y al mismo tiempo permite un proceso de interiorización y conocimiento personal (Reátegui, 2008).

Además de los factores de madurez biológica de cada niño, el contexto en el que vive resulta importante para establecer asociaciones de determinados significados con sus respectivas palabras. Por contexto se entiende desde las personas que rodean al niño, su familia, sus pares hasta su escuela, el tipo de estímulos a los que está expuesto, su comunidad y su contexto geográfico (Bronfenbrenner, 1987). Así, cuando uno de estos varía, el desarrollo semántico también se verá afectado (Bruner, 1989). Por ejemplo, se ha demostrado que existe una relación significativa y positiva entre el nivel socioeconómico y el desarrollo cognitivo, medido por el vocabulario receptivo, en países en vías de desarrollo (Cueto, León y Muñoz, 2014; Paxson y Schady, 2007). Otro factor también importante para el dominio del lenguaje es la estimulación cognitiva que recibe el niño por parte de los padres en sus primeros años de vida (Coddington, Mistry y Bailey, 2014). Por ello, cuando estos contextos varían, el desarrollo del niño será también modificado en alguna medida (Bronfenbrenner, 1987).

Uno de los elementos del contexto, y que ha sido poco estudiado en relación al desarrollo infantil, es la movilidad entre áreas geográficas rurales y urbanas. En nuestro país se ha comprobado que las diferencias de rendimiento académico entre los que viven en el campo y en la ciudad son alertantes: el 55,1\% de los estudiantes que viven en zonas urbanas se encuentran en el nivel satisfactorio de Comprensión Lectora mientras que el 18,5\% de sus pares rurales alcanzan dicho nivel (MINEDU, 2016).

Teniendo en cuenta estas diferencias según área de residencia, debe considerarse también el fenómeno de la migración que existe en nuestro país. Desde hace varias 
décadas, la migración interna principalmente manifestada en la movilización de familias que van del campo a la ciudad, ha sido uno de los procesos históricos que más han afectado la sociedad contemporánea del Perú (Yamada, 2012). En el año 1993 se reportaba que un 70\% de la población vivía en áreas urbanas, mientras que en el 2007 se incrementó al 76\% de la población (Instituto Nacional de Estadística e Informática [INEI], s.f.).

Distintos aspectos de la vida de un niño se pueden ver afectados por este tipo de movimientos, al dejar atrás un estilo de vida rural para empezar a adoptar costumbres urbanas y crecer en un entorno muy distinto al que ya estaban acostumbrados: sus relaciones sociales, sus experiencias emocionales, su desarrollo cognitivo, su distribución del tiempo y actividades, su escolaridad y aprendizajes, su uso del lenguaje, entre otros (Jelleyman y Spencer, 2008). A pesar de que muchas veces las migraciones internas se den entre zonas en las que hablan la misma lengua, los estímulos a los que está expuesto el niño varían y pueden influenciar en su desarrollo de vocabulario. Para el presente estudio se prestará especial atención a la adquisición del vocabulario, en relación a la migración, por ser una herramienta esencial para la comunicación y desarrollo cognitivo (Berko Gleason, 2010), y al mismo tiempo por ser un factor fundamental para la evidencia del nivel de nuestra educación nacional.

Existen pocos estudios que examinen específicamente la migración de un contexto rural a urbano como un factor influyente sobre la amplitud del vocabulario de los niños, más allá del nivel socioeconómico, la educación de los padres y la lengua materna de los mismo; es por ello que resulta interesante preguntarse ¿cuál es la relación que se presenta entre la migración de áreas rurales a urbanas y la amplitud del vocabulario de los niños peruanos a los ocho años de edad?

\subsection{Justificación y relevancia}

En esta investigación se examina la amplitud del vocabulario, como uno de los factores fundamentales del desarrollo cognitivo y social del ser humano, y la migración interna, como fenómeno social frecuente en las poblaciones rurales peruanas. El desarrollo del vocabulario es importante no solo por su función lingüística, sino que tiene también un valor adaptativo, pues significa un vehículo para conocer el mundo interno de cada uno y, al mismo tiempo, poder comunicarse con los demás (Reátegui, 2008). Asimismo, el 
ambiente que rodea al niño, los instrumentos culturales a su disposición y los cambios de contexto repercuten en el desarrollo individual del niño (Rogoff, 1993).

Resulta pertinente el estudio de la amplitud del vocabulario, en función a la migración, dadas las pocas evidencias específicas al respecto (Díaz, 2006) y su trascendencia y repercusión en distintos aspectos del niño: su desarrollo socioemocional, cognitivo y académico (Bruner, 1989). La investigación permitirá obtener información sobre cómo se desarrolla el vocabulario receptivo en los niños peruanos, identificando posibles influencias que surjan por la movilidad de área geográfica a la que se pueden ver expuestos y tomando en consideración las influencias del nivel socioeconómico, nivel educativo de las madres y lengua materna de los mismos, entre otros factores tanto internos como externos.

Por otro lado, en una sociedad en vías de desarrollo como la nuestra, caracterizada por la migración interna, cabe preguntarse por los efectos psicológicos y educativos que recaen sobre los niños pertenecientes a esta población, y no solo por los cambios económicos y demográficos que se originan. Los migrantes recurren a esta movilidad como respuesta a las grandes inequidades sociales y motivados por la búsqueda de mejores condiciones de vida en distintos aspectos, por lo que resulta también necesario estudiar los movimientos migratorios desde una perspectiva transversal y multidisciplinaria de modo que se pueda trabajar en una agenda regional (Novick, 2008). En Latinoamérica, y en particular en Perú, existen pocas investigaciones que registren las consecuencias del reciente y creciente fenómeno de migración sobre los niños y adolescentes (Escobal y Flores, 2009; Yamada, 2012). Conocer sobre los procesos cognitivos de los niños migrantes hará posible no solo atraer la atención hacia ellos, sino también buscar diferentes alternativas de intervención que les permitan acceder a oportunidades equitativas respecto a sus pares no migrantes.

Es de especial interés para la comunidad educativa conocer sobre el rendimiento semántico a la edad de los 8 años, que coincide con el inicio de la escolaridad y los procesos de lecto-escritura, pues el desarrollo de vocabulario tiene una repercusión importante sobre la comprensión lectora, una de las evidencias principales del nivel de rendimiento de los estudiantes. La migración también implica retos para el docente, quien deberá reconocer que el alumnado inmigrante nuevo a un centro escolar presenta necesidades educativas que pueden ser de tipo lingüístico, curricular o tutorial 
(Hernández y Habib, 2013). Tomando en cuenta la diversidad cultural y lingüística del Perú, resulta fundamental ocuparse de las necesidades de capacitación y formación de los docentes para que puedan responder a la complejidad cultural de sus alumnos, sobre todo de los inmigrantes (Reátegui, 2008). Por ello, será también importante conocer las características de los niños que migran, de modo que se pueda proveer los recursos y estrategias necesarias para su adaptación.

Este estudio permitirá complementar y ampliar las evidencias que ya existen respecto a los factores asociados al desarrollo del vocabulario, rendimiento semántico y comprensión lectora (Cueto et al., 2014; Díaz, 2006; Paxson y Shady, 2007). Asimismo se pretende aportar con evidencias del desarrollo infantil a la búsqueda de intervenciones que beneficien a las poblaciones rurales. Esta información hará posible la toma de conciencia para el planteamiento de políticas públicas, así como proyectos privados, que busquen desarrollar medidas para atender a la población migrante en los ámbitos educativos y psicosociales. 


\section{CAPÍTULO II: MARCO TEÓRICO}

\subsection{Desarrollo del vocabulario: definiciones}

El lenguaje es entendido como una forma de comunicación a partir de un sistema de símbolos; este involucra un sistema de reglas de organización, que incluyen la fonología, morfología, sintaxis, semántica y pragmática, así como también incluye una producción infinita, que se refiere a la capacidad de producir una cantidad interminable de oraciones con significado poniendo en práctica una cantidad finita de palabras y reglas (Santrock, 2007).

El desarrollo y uso del lenguaje es un proceso paulatino que comienza desde el nacimiento y significa un indicio de la construcción cognitiva en la mente de los niños (Alexander y Uccelli, 2010). Específicamente, el desarrollo del vocabulario se trata de un proceso cognitivo, con importantes implicancias para distintas dimensiones de la vida del niño: influirá en sus habilidades de comunicación, en sus relaciones sociales, aprendizajes, proceso lector, rendimiento académico, entre otros (Santrock, 2007).

Se entiende por desarrollo semántico al proceso de adquisición de las palabras que lleva a cabo el niño al relacionar estas con sus respectivos significados, es decir, se refiere al conocimiento de palabras individuales (Alexander y Uccelli, 2010; Berko Gleason, 2010; Santrock, 2007). La riqueza del vocabulario aumenta cuando se establecen mayores relaciones entre las palabras y el niño es capaz de categorizarlas; el conocimiento de las familias de palabras y las redes semánticas hacen posible un mejor desarrollo del vocabulario (Alexander y Uccelli, 2010).

Existen distintas teorías sobre el inicio de la adquisición del lenguaje; sin embargo, de cualquier manera, la representación interna del lenguaje crece y se reorganiza de forma continua con la madurez (Alexander y Uccelli, 2010). Chomsky (citado en Santrock, 2007) afirma que todos los niños cuentan con un dispositivo de adquisición del lenguaje (DAL), lo que quiere decir que todos nacen con la capacidad de comprender las características y reglas básicas del lenguaje. Por otro lado, Bruner (1989) se apoya en la teoría de Vygotski y describe que el contexto sociocultural cumple un papel fundamental en el desarrollo del lenguaje; en particular, los padres y maestros conforman un sistema de apoyo para la adquisición del lenguaje (SAAL). Esta 
postura se integra en la perspectiva interaccionista del lenguaje, explicando que tanto el DAL como el SAAL se conjugan para el desarrollo del lenguaje, destacando así el rol de la biología y de la experiencia en este proceso fundamental del desarrollo humano (Santrock, 2007).

\subsection{El desarrollo del vocabulario a lo largo de la niñez}

Los primeros años de edad son fundamentales para el desarrollo del lenguaje, dado que es en esta etapa en la que se hacen los progresos más rápidos (Berko Gleason, 2010). En los primeros meses de vida, las relaciones y manifestaciones afectivas son fundamentales para el desarrollo del lenguaje en el niño (Alexander y Uccelli, 2010; Alfonso e Ibáñez, 2013). Además, las dimensiones paralingüísticas del habla (entonación, acento, ritmos, pausas) tienen un rol importante en la comprensión del lenguaje; por ejemplo, la pronunciación lenta y entonación exagerada de los adultos facilitarán que los niños identifiquen nuevas palabras (Alexander y Uccelli, 2010; Alfonso e Ibáñez, 2013; Perinat, 2007).

La evolución del lenguaje inicia con el llanto en el nacimiento y con arrullos, es decir vocalizaciones como "cuu" o "guu", que suelen darse en interacción con el cuidador durante los primeros meses de vida (Santrock, 2007). Antes de aprender palabras, en los seis primeros meses de edad, los niños son capaces de distinguir el cambio de sonidos o de sílabas (Santrock, 2007). De forma progresiva, ingresan a la fase de balbuceo espontáneo en la que los niños empiezan a realizar combinaciones cortas de una consonante con una vocal, esta fase sucede en todas las culturas entre los seis y once meses de edad (Piaget e Inhelder, 1984; Santrock, 2007). Hasta los ocho meses de edad, el niño se encuentra en una etapa pre-lingüística, en la que responde según el tono de voz con el que se le habla y no en función a lo que se le dice; así un bebe puede responder con una experiencia positiva (por ejemplo, risas) cuando se le dicen frases negativas con un tono agradable (Alfonso e Ibáñez, 2013). A la misma edad, se halla que el desarrollo semántico es mayor a su expresión oral; es decir, el niño cuenta con mayor habilidad para comprender las palabras que para comunicarse oralmente (Perinat, 2007; Santrock, 2007).

A partir de los ocho meses de edad, el niño empieza a ser capaz de responder cuando se le llama por su nombre, a comprender una prohibición o a responder algunos 
pedidos o estímulos con diferentes gestos, por ejemplo, diciendo "no" sacudiendo la cabeza (Alfonso e Ibáñez, 2013; Santrock, 2007). Se espera que las primeras palabras sean pronunciadas desde los diez meses de edad, aunque el promedio de los niños las articulan alrededor de los trece meses; la pronunciación de la primera palabra es el hito que marca el brote del vocabulario, que sucede hacia los dieciocho meses de edad (Santrock, 2007). Hacia el final del periodo senso-motor, es decir alrededor de los dos años de edad, empieza una etapa caracterizada por las "palabras-frases", que son expresiones de deseos, emociones o comprobaciones mediante la combinación de entre tres y cinco palabras (Piaget e Inhelder, 1984; Santrock, 2007). Piaget explica que los niños necesitan el concepto de permanencia de objeto, que suele darse antes de los dos años de edad, para hacer posible la formación del símbolo en el niño para el desarrollo óptimo del vocabulario (citado en Santrock, 2007).

Alrededor de los dos años de edad se encuentra una explosión del vocabulario; es decir, un incremento intenso en la calidad de palabras que aprenden los niños (Alexander y Uccelli, 2010). Al mismo tiempo, el lenguaje de los niños evoluciona de frases de dos palabras a pequeñas frases completas aunque sin conjugaciones, para luego adquirir progresivamente las estructuras gramaticales (Piaget e Inhelder, 1984).

El desarrollo del lenguaje resulta una función adaptativa, los niños están motivados a hablar porque quieren comunicarse mejor y las palabras que tienen en su repertorio son en relación a las personas que los rodean, los objetos con los que interactúan, y las situaciones que llaman su atención (ej. comida o paseos) (Perinat, 2007). Berko Gleason (2010) sugiere además que la vida cotidiana de los niños se verá reflejada en su vocabulario en los aspectos más concretos y será muy poco probable que puedan expresarse sobre conceptos abstractos.

A los dos años de edad se encuentra un mayor dominio del lenguaje y aumento del vocabulario así como una mejora en la estructuración gramatical; se estima que se conocen alrededor de 300 palabras (Alexander y Uccelli, 2010; Santrock, 2007). Hacia la edad de tres años, los niños adquieren una función del lenguaje denominada como desplazamiento, que se refiere a la capacidad de hablar de cosas que no están físicamente presentes (Santrock, 2007). Paulatinamente, los niños entre los tres y cinco años de edad van dominando las reglas de organización del lenguaje, como las reglas fonológicas y morfológicas al saber utilizar adecuadamente el plural así como las formas posesivas de los sustantivos; paralelamente, van poniendo en práctica las reglas 
sintácticas (Santrock, 2007). Entre los cuatro y cinco años de edad empiezan a modificar el estilo de su lenguaje en función a su interlocutor; es decir, desarrollan las reglas pragmáticas del lenguaje, por ejemplo, a un niño de edad semejante le hablarán de una manera distinta de la que le hablarán a un adulto (Santrock, 2007).

Luego, en la niñez intermedia y tardía los niños desarrollan un pensamiento más analítico y lógico para el uso de las palabras (Santrock, 2007); el ingreso a la educación primaria hace posible que los niños desarrollen un vocabulario más complejo, empiecen a categorizar las palabras en agrupaciones semánticas, usen las palabras de manera interconectada y adquieran las habilidades requeridas para aprender a leer y escribir (Berko Gleason, 2010; Santrock, 2007). Se estima que a los seis años de edad, un niño conoce entre 8,000 y 14,000 palabras (Santrock, 2007). Entre los dos primeros años de escolarización, cuando los niños tienen entre seis y ocho años, surgen los mayores cambios de la escolaridad en cuanto a los procesos semánticos dadas la estimulación y la evolución cognitiva (Berko Gleason, 2010). Hacia los ocho años, los niños tienen mejor delimitadas las categorías de palabras así como un mayor dominio de las clasificaciones sintácticas de las palabras (Berko Gleason, 2010). Es así como se empiezan a sentar las bases para su desarrollo académico posterior, que implicará mayores relaciones conceptuales así como mayor complejidad en la lectura (Berko Gleason, 2010; Santrock, 2007).

\subsection{Factores asociados al desarrollo del vocabulario}

Los factores que influyen en el vocabulario son diversos pues existe una amplia variabilidad individual en términos de desarrollo semántico; estos son tanto individuales como ambientales (Alexander y Uccelli, 2010; Walker et al., 2007). En relación a los aspectos biológicos del lenguaje, se debe tener en cuenta que además del aparato vocal, el hemisferio izquierdo del cerebro está altamente involucrado en el lenguaje (Santrock, 2007). Son dos de sus áreas las que permiten el desarrollo y práctica del lenguaje: el área de Broca, que es la zona del lóbulo frontal izquierdo del cerebro que controla los movimientos musculares para la articulación del lenguaje; y el área de Wernicke, que se relaciona con la comprensión del lenguaje (Santrock, 2007).

Entre los factores individuales destaca la capacidad intelectual que puede tener un niño para asociar y recordar estímulos o palabras, que suele estar relacionada al área 
de Wernicke (Marchman y Fernald, 2008). Asimismo, influye el estado nutricional del niño y su desarrollo saludable. Este suele ser explicado por variables antropométricas y se encuentra que tiene un rol importante en la cognición y el lenguaje (Verdisco, Cueto, Thompson y Neuschmidt, 2015). Distintos estudios encuentran relaciones significativas entre una talla menor de lo esperada para la edad (que suele utilizarse para indicar retraso en el crecimiento) y retraso en el desarrollo cognitivo y lingüístico (Paxson y Schady, 2007; Rubio-Codina, Attanasio, Meghir, Varela y Grantham-McGregor, 2013; Verdisco et al., 2015; Walker et al., 2007). Por ejemplo, Paxson y Schady (2007) encuentran que el incremento de una desviación estándar en la variable de talla para la edad está asociada con el incremento de 1.2 puntos en el puntaje de Test de Vocabulario en Imágenes Peabody (TVIP). Asociaciones similares se encuentran entre el peso del niño al nacer y el desarrollo de su vocabulario a los 30 meses de edad (Henrichs et al., 2011).

Respecto a los factores ambientales, Bruner (1989) sostiene que el conocimiento del mundo que tiene el niño influenciará su adquisición del lenguaje. Al mismo tiempo, Bronfenbrenner (1987) explica la teoría ecológica del desarrollo humano, asegurando que las propiedades cambiantes del entorno son fundamentales en el desarrollo de la persona, la cual es un ser activo y dinámico que se ve influenciado por las relaciones que se establecen en sus entornos inmediatos y por los contextos más amplios a estos.

La teoría de Bronfenbrenner (1987) propone una clasificación de sistemas o ambientes ecológicos, en función a la proximidad de dichos entornos con la persona en desarrollo. Esta clasificación tiene una estructura concéntrica en la que cada ambiente ecológico está contenido en el siguiente. El primer sistema, el de mayor proximidad a la persona en desarrollo, es el microsistema que incluye las actividades, roles y relaciones interpersonales experimentadas por la persona en espacios concretos en los que se puede interactuar cara a cara, como el hogar o la guardería. El mesosistema es el siguiente ambiente ecológico que se caracteriza por las interrelaciones de dos o más entornos en los que la persona participa activamente; por ejemplo, las relaciones entre el hogar y la escuela. El exosistema es aquel en el que la persona no es un participante activo pero los hechos que se llevan a cabo le afectan a ella o a sus entornos de mayor proximidad; por ejemplo, el trabajo de sus padres o las actividades del consejo escolar del barrio. Finalmente, el macrosistema abarca las relaciones y correspondencias entre los entornos anteriores e incluye a la cultura o sistema de creencias en su totalidad, en la 
cual crece el niño y se transmite a la siguiente generación; por ejemplo, el macrosistema de una familia acomodada no será el mismo que el de una familia más pobre.

Bronfenbrenner (1987) indica que los esquemas de sistemas son diferentes según grupos socio-económicos, étnicos, religiosos, etc. pero además a lo largo de la vida varían para una misma persona, que está en constante movimiento y desarrollo. Cuando una persona cambia de entorno o pasa por un cambio de rol ocurre una transición ecológica; estos cambios pueden ser de todo tipo y en cualquier nivel de los sistemas, por ejemplo, cambiar de cuidador, ingresar a la guardería, tener un nuevo hermano, salir del colegio e ingresar a la universidad, más adelante cambiar de trabajo, salir de vacaciones, casarse, mudarse de ciudad, jubilarse, entre otros (Bronfenbrenner, 1987). Las transiciones ecológicas ocurren durante toda la vida, conjugan la adaptación de los cambios biológicos con los del entorno ya que son tanto antecedentes como consecuencias del desarrollo (Bronfenbrenner, 1987).

Paralelamente a los factores individuales, aseguran Alexander y Uccelli (2010) y teniendo en cuenta que el macrosistema tiene un gran impacto sobre los demás sistemas que forman parte del contexto del niño (Reátegui, 2008), es fundamental disponer de un entorno lingüístico que promueva la riqueza semántica, ya sea desde la familia, la escuela, los pares hasta los medios de comunicación y accesibilidad a otros medios de lectura. Lo que el niño interioriza es lo que ha realizado previamente en su contexto social: la interacción con otras personas y su nivel de habilidad en relación a diferentes instrumentos culturales, influye en el desarrollo individual del niño (Rogoff, 1993).

La riqueza cultural del hogar ha sido estudiada mediante la cantidad de libros con los que cuentan los niños en sus casas y los hábitos de lectura de sus padres, y se encuentra que estos factores son significativos para predecir el desarrollo del vocabulario (Farrant, Shepherd, Walker y Pearson, 2014; Verdisco et al., 2015). Sin embargo, la riqueza cultural también suele estar relacionada con la situación económica a pesar de que esta última no debería significar una barrera para la capacidad léxica (Alexander y Uccelli, 2010). Un estudio realizado en 28 países en vías de desarrollo (Bornstein y Putnick, 2012), encuentra que solo un tercio de las madres participantes leían libros o contaban cuentos a sus hijos; estas actividades, entre otras, se consideran estimulantes para el desarrollo cognitivo de los niños y por lo tanto resulta urgente promoverlas en países en desarrollo. De la misma forma, el estudio de Takeuchi et al. (2016) muestra cómo, tanto a nivel fisiológico como intelectual la lectura repercute 
sobre el niño. En dicho estudio se evidencia que hábitos de lectura consolidados afectan positivamente determinadas zonas del cerebro (el fascículo arqueado izquierdo, el fascículo fronto-occipital inferior izquierdo, y la corona radiata posterior izquierda) así como también benefician la comprensión verbal.

Se encuentran diferencias en el desarrollo del vocabulario entre distintos ambientes socioculturales, evidenciando que una mayor riqueza sociocultural beneficiará el desarrollo cognitivo y semántico del niño (Alfonso e Ibáñez, 2013; Coddington et al., 2014; Cueto et al., 2014; Díaz, 2006; Farrant et al., 2014; Henrichs et al., 2011; Paxson y Schady, 2007; Rubio-Codina et al., 2013; Schady et al., 2014; Verdisco et al., 2015). Aquellos contextos desfavorecidos presentan evidencias de un lenguaje más reducido en cuestión de vocabulario, es más simple y concreto, la conceptualización es escasa y las oraciones son breves; mientras que en ambientes socioculturalmente favorecidos, el lenguaje es más rico y complejo en palabras y conceptualizaciones (Alfonso e Ibáñez, 2013).

Cueto et al. (2014) estudiaron la asociación entre la calidad de los servicios de las escuelas, su nivel socioeconómico y el rendimiento académico de los niños en distintos momentos de su crecimiento en el Perú. Para los niños de 5 años de edad, encuentran brechas en el desarrollo del vocabulario, en función a la educación de la madre y lengua materna. Estas diferencias son similares a las que se presentan en ellos a sus 8 años de edad. Concluyen que el mejor predictor de los resultados educativos es el nivel educativo de la madre, indistintamente de la edad que tengan los niños. Asimismo, enfatizan que lo niños que provienen de familias en desventaja tienen menores oportunidades educativas desde la edad de los tres años y estas diferencias continúan hasta los 8 años de edad. Se evidencia así un círculo vicioso en la educación, en el que mayor peso cobra las condiciones del contexto en el que nace el niño y poco poder presenta el estado para ofrecer oportunidades diferentes y mejores.

Un estudio realizado por Paxson y Schady (2007) en Ecuador, buscó identificar la relación entre el desarrollo cognitivo y el nivel socioeconómico, la salud del niño y la calidad de crianza. Usaron el Test de Vocabulario en Imágenes Peabody (TVIP) como medida de desarrollo cognitivo y hallaron que el nivel socioeconómico y la educación de los padres guardan una relación significativa con el desarrollo del vocabulario; esta relación será más intensa en el niño cuando tenga mayor edad. 
Por otro lado, en estudios realizados de manera paralela en diferentes países de Latinoamérica, se confirma que el nivel socioeconómico es uno de los factores más influyentes en el desarrollo temprano de los niños. Verdisco et al. (2015) analizaron distintas dimensiones del desarrollo de la primera infancia en Costa Rica, Nicaragua, Paraguay y Perú y encontraron que la desigualdad en estas dimensiones aparece a partir de los 24 meses de edad y se va incrementando en el tiempo. Las factores que tienen mayor peso al intervenir sobre el desarrollo cognitivo, lingüístico y comunicacional son las características socioeconómicas del hogar y el nivel educativo de la madre; son estos factores los que van ampliando las brechas de desigualdad. Asimismo consideran importante el ambiente en el que se desarrollan los niños, definiéndolo por las interacciones de los padres con sus hijos, el material lúdico y educativo disponible por niño y las rutinas de higiene, entre otros.

Paralelamente, Schady et al. (2014) desarrollan un estudio similar en cinco países de la región (Chile, Colombia, Ecuador, Nicaragua y Perú), identificando también que el mayor factor influyente en la desigualdad de desarrollo infantil es el estatus socioeconómico. Igualmente, en Colombia, Rubio-Codina et al. (2013) encuentran evidencias de la influencia de la riqueza sobre el desarrollo cognitivo y de vocabulario receptivo y expresivo. Coddington et al. (2014) identifican que además del factor socioeconómico, otras variables intervienen sobre el desarrollo del vocabulario receptivo: entre varias, destacan el nivel educativo de los padres, la estimulación cognitiva y lingüística que reciben los niños y el tipo de escuela al que asisten.

\subsection{El rol de la migración como contexto de desarrollo}

La teoría de Vygotski (Santrock, 2007) es de carácter sociocultural cognoscitiva y propone la importancia de la cultura y de la interacción social para el desarrollo cognoscitivo. Afirma que el desarrollo del niño es inseparable de las actividades sociales y culturales. Así, los conocimientos (como el de nuevas palabras) podrán mejorarse con nuevas interacciones sociales. Se podría decir entonces que el factor fundamental del desarrollo es el aprendizaje que se logra por la intermediación de la influencia de las otras personas (Riviére, 1996). Rogoff (1993) coincide, asegurando que el desarrollo del lenguaje tiene una base social, en la que el manejo del lenguaje de 
los padres y las personas con las que se relaciona el niño repercute sobre el lenguaje de éste último.

Una investigación longitudinal llevada a cabo en Canadá por Brownell et al. (2016) estudia el desarrollo de la primera infancia. Encuentran que, tomando en cuenta una combinación de factores (condiciones pre-natales, salud al nacer, riesgo familiar y nivel socioeconómico del vecindario o comunidad), los riesgos que presenta la familia del niño (definidos por: ausencia de beneficios sociales, bajos ingresos, madres adolescentes durante su embarazo, más de cuatro niños en la familia y depresión de la madre) es el que tiene una correlación más fuerte y negativa con el desarrollo lingüístico y cognitivo del niño al iniciar la escuela primaria. A su vez, estos factores de riesgo familiar están influenciados por su contexto vecinal (para definirlo se toma en cuenta el desempleo de los vecinos, un promedio bajo de sus ingresos y el nivel educativo de los mismos). Los resultados sugieren que, si bien las intervenciones que se enfocan en los factores individuales del niño resultan efectivas, las intervenciones y políticas que se enfocan en las comunidades y las familias son las que pueden tener el mayor impacto en el desarrollo de la infancia.

Desde una perspectiva psicosocial, la urbe es un espacio de interacción, en sus calles, edificios, plazas lleva a cabo la mayor parte de la vida cotidiana de un ciudadano (Romay, López-Corton y Gil, 2012). Tanto la sociedad urbana como la migración repercuten en las personas en distintas dimensiones: actitudes, estereotipos, comunicación, identidad social, formación de grupos (Escobal y Flores, 2009). Los procesos migratorios suelen implicar desarraigo de las interacciones sociales ya conocidas; implica una separación los vecinos, familiares, amigos y otras personas a las que se conocía de toda la vida y con las que se habían establecido vínculos (Santrock, 2007).

En un estudio desarrollado en España (Romay et al., 2012), que busca recoger información sobre los patrones de migración, se encuentra que los inmigrantes desarrollan nuevas relaciones sociales, que se caracterizan por ser más impersonales y se encuentra mayor individualismo frente a las relaciones vecinales que mantenían en espacios rurales. Los autores concluyen que estos nuevos estilos repercuten en las comunicaciones interpersonales y por ende, en el lenguaje. 
Entre las pocas evidencias de la influencia del área geográfica en el desarrollo infantil, Mastin y Vogt (2015) desarrollan un estudio longitudinal sobre la adquisición del lenguaje en comunidades de Mozambique, con el objetivo de hacer comparaciones entre estas comunidades respecto a cómo aprenden los niños sus primeras palabras. Confirman que las relaciones que desarrollan los niños consigo mismos o con otras personas en los primeros meses de vida tienen influencias significativas con la amplitud del vocabulario que alcanzarán en los años posteriores. Describen que los participantes de la comunidad urbana tienden a estar expuestos a un contexto social más dinámico por la densidad demográfica, la industria y tecnología. En cuanto al contexto familiar, la mayoría de los padres rurales de estas comunidades tenían muy bajos niveles educativos, en contraste con los padres urbanos. Los resultados muestran que los niños rurales pasan la mayor parte del tiempo en espacios solitarios (por ejemplo, observa a otros, juega consigo mismo o con determinados objetos), mientras que los niños urbanos tienen más relaciones triádicas (es decir, que el niño interactúa con otros individuos o grupos sociales en torno a un propósito determinado). Estas distinciones en sus relaciones repercuten de manera diferenciada en su aprendizaje de vocabulario: cuando el niño interactúa con otras personas teniendo un propósito común se asocia positivamente con el desarrollo del vocabulario en comunidades urbanas pero tiene el efecto contrario en las comunidades rurales. Esto demuestra que los espacios y contextos de aprendizaje varían entre las comunidades situadas en zonas urbanas y rurales. Sin embargo, para ambas comunidades sucede que las situaciones en las que el niño interactúa con otras personas sin un objeto concreto en común se relacionan positivamente con el desarrollo del vocabulario, entendiéndose como un potencial para este dominio.

\subsection{Importancia del desarrollo del vocabulario en procesos cognitivos}

Vygostki (citado en Riviére, 1996) explica que para entender los logros de aprendizaje del niño no se debe tomar en cuenta únicamente lo que este es capaz de hacer por sí mismo sino también las capacidades que puede alcanzar con la ayuda de otras personas; a esto lo llama la "zona de desarrollo próximo". Para Vygotski, el habla no significaba solamente un medio de comunicación sino también una herramienta fundamental para el desarrollo cognoscitivo (Santrock, 2007). El autor postula que el desarrollo cognitivo implica un proceso de construcción social; de esta manera, se entiende que el desarrollo 
cognitivo y lingüístico están significativamente relacionados y no solo depende de la maduración biogenética sino también de la interacción social (Alfonso e Ibáñez, 2013).

Los niños que empiezan la educación primaria con un vocabulario reducido presentan mayores riesgos para desarrollar problemas de lectura (Berko Gleason, 2010). En el Perú, estos niños suelen ser aquellos cuyas madres presentan menores niveles educativos y/o que tienen una lengua indígena como la materna; tienen menores probabilidades de asistir a un centro pre-escolar y por ello, de presentar desventajas cognitivas a los 5 años edad (Cueto et al., 2014). Se cuenta con evidencia que la asistencia a centros pre-escolares formales beneficia la amplitud del vocabulario a los cinco años de edad (Cueto et al., 2016). Snow (citada en Santrock, 2007) afirma que los niños que, antes de entrar a la educación primaria, presentan desventajas en habilidades verbales, conciencia fonológica, y conocimiento de letras encontrarán mayores probabilidades de desarrollar problemas en el proceso lector.

Un prerrequisito fundamental para aprender a leer es la capacidad de comprensión de las palabras (Berko Gleason, 2010). Así, el vocabulario y la comprensión lectora están estrechamente relacionados, pues es necesario que los niños entiendan el significado de las palabras para poder comprender el contenido del texto. Si los niños no presentan una amplitud de vocabulario determinada para su edad, será muy posible que muestren dificultades para lograr el éxito académico ya que no comprenderán el lenguaje oral y escrito para distintas áreas curriculares (Alexander y Uccelli, 2010).

De esta forma, se concluye que comprender y atender el proceso de adquisición de vocabulario es fundamental para el desarrollo académico, cognitivo, personal y social. Es de particular importancia estudiar la situación lingüística de los niños más pequeños que viven en zonas más vulnerables, con menores oportunidades dado que es en las edades más tempranas en las que las intervenciones podrían cobrar mayores efectos para lograr una equidad de oportunidades. Tomando en cuenta las mencionadas teorías de Bronfenbrenner (1987), Bruner (1989) y Vygotski (Riviére, 1996), será de especial relevancia poner la atención sobre los factores contextuales que hacen posible, o dificultan, el desarrollo lingüístico de los niños. 


\section{CAPÍTULO III: OBJETIVOS, HIPÓTESIS Y DEFINICIÓN DE VARIABLES}

\subsection{Objetivos}

Examinar en qué medida la migración temprana y tardía de áreas rurales a otras urbanas predicen la amplitud del vocabulario receptivo de los niños peruanos a los ocho años de edad.

\subsection{Hipótesis}

Dado que el desarrollo del vocabulario es un proceso influenciado por el ambiente sociocultural en el que crece el niño y el conocimiento que este tiene del mundo (Alfonso e Ibáñez, 2013; Bruner, 1989), se espera que la presente investigación evidencie diferencias en la amplitud del vocabulario de los niños, a partir de la experiencia de migración de áreas rurales a otras urbanas. Se presentan a continuación las dos hipótesis del estudio:

$\mathrm{H}_{1}$ : Se estima que migrar a un área urbana tendrá una influencia positiva sobre la amplitud del vocabulario receptivo que presentan los niños a los ocho años de edad. Es decir, el niño rural que migró a una zona urbana presentará mejores resultados que los que permanecieron en zonas rurales, en cuanto a la medida de vocabulario receptivo.

$\mathrm{H}_{2}$ : Se espera que migrar a edades más tempranas (y por lo tanto contar con mayores probabilidades de estar más expuesto a contextos estimulantes del desarrollo lingüístico) predice un mayor rendimiento en cuanto al vocabulario, tomando en cuenta que "la explosión del vocabulario" se da alrededor de los dos años de edad (Alexander y Uccelli, 2010; Santrock, 2007).

\subsection{Definición de variables}

El presente estudio trabaja con tres variables de exploración y once de control: 


\subsubsection{Variable dependiente}

En primer lugar, se estudia la amplitud del vocabulario como variable predicha o dependiente (Field, 2009). Esta hace referencia al proceso semántico de adquisición de palabras que se da desde los primeros meses de edad y continúa a lo largo de toda la vida (Alexander y Uccelli, 2010; Berko Gleason, 2010; Santrock, 2007). Esta variable es continua y se refiere a la cantidad de palabras comprendidas de modo oral, medida con el Test de Vocuabulario en Imágenes Peabody [TVIP] (Dunn, Padilla, Lugo y Dunn, 1986). Los valores que se utilizarán para los análisis corresponden al puntaje rasch, que se obtiene a partir del puntaje directo y permite calcular las habilidades del niño y la dificultad de los ítems en una misma escala. Los puntajes directos pueden tomar valores desde 0 hasta 125 , que corresponde al total de ítems de la prueba (cada respuesta correcta tiene valor de 1). Para esta muestra, los valores correspondientes al puntaje directo están comprendidos entre 1 y 122, y los valores rasch para dichos puntajes fluctúan entre 243 y 342.

\subsubsection{Variables predictoras}

Las dos variables predictoras de interés son las de migración interna: migración temprana y migración tardía. La migración interna hace referencia a los cambios de localidad residencial dentro de un mismo país; es un movimiento que en los últimos años se ha caracterizado en Latinoamérica por la movilidad de áreas rurales hacia las ciudades (UNICEF, 2006).

Las distinciones de rural y urbano se basan en las definiciones descritas por el INEI (s.f.), en las que el área urbana es descrita como el territorio de un distrito conformado por uno o más centros poblados urbanos (agrupamiento de mínimo 100 viviendas contiguas que forman calles y manzanas). También son considerados centros poblados urbanos las capitales de distrito, incluso si estas no cumplan con el criterio mínimo de viviendas. Por su parte, el área rural es el territorio de un distrito comprendido por los centros poblados rurales (aquellos que no tienen 100 viviendas contiguas, ni son capital de distrito, o que teniendo más de 100 viviendas, estas se encuentran dispersas). Estos centros poblados rurales se extienden desde los linderos de los centros poblados urbanos hasta los límites del distrito. 
Para el presente estudio se entenderá por migración interna al cambio de una localidad residencial rural a una localidad residencial urbana. La información se obtendrá a partir de la comparación entre los datos geográficos de residencia reportados en el "Cuestionario de Niños 6-17.9 meses Perú - 2002" y los datos geográficos de residencia reportados en el "Cuestionario del Hogar - Perú. Niños de 5 años - 2006" y en el "Cuestionario del Hogar Niños de 8 años, Perú - 2009"; estos tres cuestionarios mencionados pertenecen al estudio longitudinal Niños del Milenio. Los datos geográficos de residencia son reportados por los padres de los niños y son denominados como rural o urbano según la clasificación del INEI.

Para efectos del modelo, la migración interna se compone de dos variables: migración temprana y migración tardía. Ambas son variables categóricas nominales y dicotomizadas, correspondiendo a la metodología dummy (Field, 2009), con dos posibles valores cada una. A continuación se describen operacionalmente:

i. La variable de migración temprana toma valor de 1 para indicar que el niño migró de un contexto rural a uno urbano entre sus dos y cinco años de edad. Es decir, el dato geográfico de residencia obtenido en el año 2006 y en el 2009 corresponde a "urbano". En caso contrario, adopta el valor de 0.

ii. El valor de 1 para la variable de migración tardía expresa que el niño (que hasta el año 2006 vivía en un contexto rural) se mudó a un contexto urbano entre sus cinco y ocho años de edad. Esto significa que en el año 2006 el dato geográfico de residencia corresponde a "rural" pero en el año 2009 corresponde a "urbano". En caso contrario, tiene valor de 0 .

iii. Ambas variables tomarán valor de 0 cuando para indicar que el niño no migró, permaneciendo en un área rural hasta sus ocho años de edad. Es decir, el dato geográfico de residencia corresponde a "rural” en el año 2002, 2006 y 2009.

\subsubsection{Variables de control}

Se toman en cuenta once variables de control, es decir, aquellas que podrían estar modulando la influencia de la variable independiente (Keith, 2015). Estas han sido 
seleccionadas a partir de experiencias previas en las que se ha evidenciado el rol predictor que tienen sobre el desarrollo de vocabulario (Coddington et al., 2014; Cueto et al., 2014; Díaz, 2006; Farrant et al., 2014; Henrichs et al., 2011; Paxson y Schady, 2007; Rubio-Codina et al., 2013; Schady et al., 2014; Verdisco et al., 2015). Dichas variables son las siguientes:

i. Sexo del niño/a: Se entiende por sexo a la condición biológica que distingue a los hombres de las mujeres (Real Academia Española [RAE], 2014). Esta información es reportada por los padres de los niños mediante el "Cuestionario de Niños 6-17.9 meses Perú - 2002”. Sus posibles valores son 1 para femenino ó 0 para masculino.

ii. Edad: Significa el tiempo que ha vivido una persona desde su nacimiento (RAE, 2014). La edad cronológica del niño se reporta como la cantidad meses que han transcurrido desde su fecha de nacimiento (reportada por los padres en el “Cuestionario de Niños 6-17.9 meses Perú - 2002”) hasta la fecha de la evaluación del TVIP, ocurrida en el año 2009.

iii. Talla para la edad: Se refiere a la medida antropométrica de la relación entre la altura del niño (medida en centímetros) y su edad (medida en meses), suele entenderse como un indicador nutricional del niño (Verdisco et al., 2015). Es una variable continua que se expresa mediante un puntaje $Z$, correspondiente a la comparación de la altura del niño medida en el 2002 frente a la altura media internacional que se espera para la edad, según los criterios de la Organización Mundial de la Salud (Cueto, Escobal, Penny, y Ames, 2012; Henrichs et al., 2011).

iv. Índice socioeconómico del hogar: Es la representación numérica que expresa la relación de ciertas características sociales y económicas de manera conjunta (RAE, 2014). Varios estudios en la región han identificado que a mayor nivel socioeconómico, mayor amplitud del vocabulario (Coddington et al., 2014; Cueto et al., 2014; Paxson y Schady, 2007; Rubio-Codina et al., 2013; Schady, 2014; Verdisco et al., 2015). Para el presente estudio, este índice se compone 
por el bienestar de los miembros del hogar respecto a la calidad de la vivienda (ratio del número de habitaciones en el hogar, material del techo, paredes y piso), uso de bienes duraderos (tenencia de electrodomésticos y vehículos) y acceso a los servicios básicos (electricidad, agua entubada, fuente de combustible y servicios higiénicos). Estos datos han sido reportados por los padres de los niños mediante el "Cuestionario de Niños 6-17.9 meses Perú 2002". Se utiliza el índice de riqueza del hogar para el año 2002 por ser el momento que representa la etapa más crítica para el desarrollo del vocabulario para los sujetos de la muestra (Alexander y Uccelli, 2010; Santrock, 2007). El índice socioeconómico del hogar es una variable continua con un rango de valores entre 0 y 1 , este último valor representa las mejores condiciones socioeconómicas.

v. Nivel educativo de la madre: Se entiende por nivel educativo a la clasificación de los grados de educación formal que una persona puede alcanzar; los niveles educativos designados por el Estado del Perú son: inicial, primaria, secundaria y superior (Ley General de Educación, 2003). Diferentes estudios han señalado la importancia del máximo nivel educativo completado por la madre sobre el desarrollo lingüístico y cognitivo del hijo (Coddington et al., 2014; Cueto et al., 2014; Paxson y Schady, 2007; Verdisco et al., 2015). El nivel educativo de la madre (o del cuidador principal) se conoce mediante el "Cuestionario de Niños 6-17.9 meses Perú - 2002". Para efectos del modelo, esta es una variable dicotómica que toma valor de 1 si la madre alcanzó completar la secundaria o niveles superiores y toma valor de 0 si tiene niveles educativos inferiores a la secundaria completa.

vi. Lengua materna en el hogar: Se define como lengua materna al idioma que una persona aprende en su entorno familiar y mediante el cual se comunica normalmente (RAE, 2014). Estudios como el de Cueto et al. (2014) predicen que tener una lengua nativa como lengua está relacionada a un menor rendimiento en evaluaciones cognitivas. En el presente estudio, los padres reportan mediante el “Cuestionario de Niños 6-17.9 meses Perú - 2002” la 
lengua que utilizan ambos padres y la que aprendió primero el niño. Si ambos padres y/o el niño aprendieron como primera lengua una lengua indígena (quechua, aimara o alguna lengua originaria de la selva), esta variable toma valor de 1. En caso contrario (si la lengua materna es el castellano), toma valor de 0 .

vii. Educación inicial del niño: En el sistema educativo peruano, la educación inicial es el primer nivel de la Educación Básica Regular y se ofrece de forma escolarizada a niños entre los 3 y 5 años de edad (Ley General de Educación, 2003). Cueto et al. (2016) y Santrock (2007) discuten la importancia de asistir a un centro de educación inicial para un mejor desarrollo lingüístico y cognitivo. Esta información es reportada por los padres mediante el "Cuestionario del Hogar Niños de 8 años, Perú - 2009”. Esta variable es dicotómica y toma valor de 1 si el niño, entre sus tres y cinco años de edad (en el rango del 2004 al 2007), ha asistido en al menos un año a un Centro de Educación Inicial (CEI). Adopta el valor de 0 en caso contrario.

viii. Educación primaria del niño: En el sistema educativo peruano, es el segundo nivel de la Educación Básica Regular, es de carácter obligatoria y tiene una duración de seis años; el primer grado de primaria se ofrece a niños de seis años de edad (Ley General de Educación, 2003). Diversos estudios demuestran el rol de la escuela sobre el desarrollo cognitivo (Alexander y Uccelli, 2010; Coddington et al., 2014). Los datos al respecto se obtienen del reporte de los padres en el "Cuestionario del Hogar Niños de 8 años, Perú - 2009". Esta variable dicotómica toma valor de 1 si el niño, entre sus cinco y ocho años de edad (entre el año 2006 y 2009), ha asistido al menos un año a una Institución Educativa primaria. En caso contrario, toma el valor de 0.

ix. Recibe ayuda de los padres en las tareas escolares: Esta variable permite aproximarse a la estimulación de lenguaje y conocimientos que pueden estar transmitiendo los padres a los hijos con un objetivo académico en el hogar (Bornstein y Putnick, 2012). La información se recoge mediante el reporte de 
los padres en el "Cuestionario del Hogar Niños de 8 años, Perú - 2009” y toma valor de 1 si se reporta que el padre o la madre brindan ayuda al niño en sus tareas del colegio, a la edad de 8 años. En caso contrario, toma el valor de 0.

x. Lectura por entretenimiento: Dezcallar et al. (2014) y Takeuchi et al. (2016) demuestran que los hábitos de lectura recreativa fuera del horario escolar permite incrementar su vocabulario y fluidez verbal. Esta variable es dicotómica y toma valor de 1 si los padres reportan en el "Cuestionario del Hogar Niños de 8 años, Perú - 2009" que su hijo suele leer como entretenimiento, a la edad de 8 años. Toma valor de 0 si reportan que el niño no manifiesta esta conducta.

xi. Cantidad de libros en el hogar: La cantidad de libros que el niño tenga a su disposición fomentaría los hábitos de lectura y con ello, el desarrollo del vocabulario (Farrant et al., 2014; Verdisco et al., 2015). Sin contar los libros de texto de la escuela, esta variable dicotomizada toma valor de 1 si los padres reportan en el "Cuestionario del Hogar Niños de 8 años, Perú - 2009” que en el hogar del niño tienen seis o más libros para leer. Toma valor de 0 si tienen cinco o menos libros en el hogar. 


\section{CAPÍTULO IV: METODOLOGÍA}

\subsection{Tipo y diseño de investigación}

El diseño de la investigación que se lleva a cabo es no experimental transeccional dado que no se manipulan las variables, sino que se realiza la medición de la variable dependiente (amplitud del vocabulario) en un momento único en el tiempo (Hernández, Fernández y Baptista, 2014). La investigación es de tipo correlacional-causal ya que se establecen relaciones entre las variables del estudio y se analiza retrospectivamente mediante un análisis multivariado el rol predictor que tienen determinadas variables de un mismo grupo muestral sobre su puntaje del vocabulario receptivo (Hernández et al., 2014).

\subsection{Participantes}

Se utilizan datos secundarios, es decir, información que ha sido recolectada por otros investigadores (Hernández et al., 2014). Los datos utilizados en la presente investigación corresponden a los participantes del estudio longitudinal Niños del Milenio en el Perú, que se caracteriza por retratar el desarrollo de los niños que viven en pobreza y es representativo de esta población.

Dicho estudio eligió estudiar a 2,000 niños, que en el primer momento del recojo de información (año 2002) tenían entre 6 y 18 meses de edad. El número de niños se eligió por ser una cantidad viable para el seguimiento a lo largo de los años y, al mismo tiempo, cantidad suficiente para los análisis estadísticos (Escobal et al., 2003). Se eligió aleatoriamente a 100 niños de 20 comunidades llamadas "centinelas". El término "centinela" se refiere a que estas comunidades son representativas de un tipo específico de comunidad. Es decir, lo que ocurre en esta comunidad se espera que ocurra en otras comunidades con las mismas características. El número de niños seleccionados por comunidad es lo suficientemente grande como para ser representativo por estrato (Escobal et al., 2003). Además, tener la misma cantidad de participantes en cada comunidad beneficia la comparación entre las mismas.

Para la elección de los participantes se realizó un muestreo por racimos mediante selección sistemática, el cual se explica a continuación. Se utilizó inicialmente 
un marco distrital, tomando en cuenta el mapa oficial de pobreza del FONCODES 2000, el cual clasifica a los distritos tomando como criterios: mortalidad infantil, tipo de vivienda, grados de escolaridad de la población, vías de acceso y disponibilidad de servicios básicos (Escobal et al., 2003). Se excluyó al 5\% de los distritos más ricos del país dado que el estudio tiene un énfasis en la pobreza. Se ordenaron los distritos según la clasificación de pobreza mencionada, y seleccionando aleatoriamente un punto de partida se tomó una muestra sistemática de los distritos utilizando los datos poblacionales. Se realizaron en total diez muestras sistemáticas de las cuales se eligió la séptima, que fue la que mejor se adecuaba a las características del estudio, considerando la cobertura de zonas rurales, urbanas, peri urbanas y selváticas, además de la viabilidad logística (Escobal et al., 2003).

Al tener la selección de distritos se prosiguió con el censo de casa por casa para identificar los hogares con niños de aproximadamente un año de edad. Para ello se seleccionó de manera aleatoria un centro poblado dentro de cada distrito y se contó el número de manzanas. Finalmente, dentro de los centros poblados seleccionados se asignaron las manzanas contabilizadas a distintos trabajadores de campo. Cada vivienda de las manzanas fue visitada para buscar niños de la edad de interés (Escobal et al., 2003).

Hasta el presente se han realizado cuatro rondas de levantamiento de información a los mismos participantes como parte del estudio Niños del Milenio en los años 2002, 2006, 2009 y 2012. En esta investigación se trabaja con los datos recogidos hasta el 2009, y que correspondan a los niños nacidos en el Perú entre los años 2000 y 2002 en áreas rurales. Se elige recoger la información de los niños desde sus primeros meses de edad por ser cruciales para el desarrollo lingüístico y se busca encontrar los predictores en el desarrollo del vocabulario hasta sus ocho años de edad, por ser una etapa que marca el inicio de la escolaridad y se relaciona con los procesos de lectoescritura (Berko Gleason, 2010). Además, es alrededor de esta edad en la que los niños peruanos desempeñan las evaluaciones censales administradas por el Ministerio de Educación.

Se enfatiza en el área rural con el fin de analizar con exclusividad las características de esta población, que se conoce como la más desfavorecida frente a la urbana, en cuanto a tasas de analfabetismo, provisión insuficiente de servicios básicos, 
ausencia de planificación de transporte y territorial, entre otros (Fondo Internacional de Desarrollo Agrícola [FIDA], 2013).

Para determinar el tamaño de la muestra de la presente investigación se tomaron en cuenta dos criterios: los estudios previos con variables similares y la disponibilidad de datos del estudio Niños del Milenio. En primer lugar, estudios similares (Cueto et al., 2014; Farrant et al., 2014) encuentran un tamaño del efecto alrededor de $\mathrm{f}^{2}=.30$. De manera que si en la presente investigación se pretende hallar un tamaño del efecto grande, $\mathrm{f}^{2}=.35$ (Cohen, 1992) con una potencia estadística de .99 , se debería contar con una muestra de al menos 103 participantes según el análisis computado mediante G*Power. En segundo lugar, se evalúa la sensibilidad del tamaño de la muestra disponible del estudio Niños del Milenio, que se explica a continuación.

De los 646 sujetos que habitaban áreas rurales en el recojo de información del estudio Niños del Milenio al 2002, se excluyeron a aquellos que eligieron rendir el TVIP en quechua ya que este tipo de evaluación no es comparable con el TVIP en castellano. Además, se incluye en la muestra solo a aquellos que tienen los datos completos para todas las variables utilizadas en el presente estudio. De esta forma, la muestra está conformada por 445 niños en total. Al evaluar su sensibilidad mediante G*Power, se encuentra que dicho tamaño es lo suficientemente sensible para detectar un tamaño del efecto entre pequeño y moderado, $\mathrm{f}^{2}=.07$ teniendo una potencia estadística de .99 (Cohen, 1992; Faul, Erdfelder, Lang y Buchner, 2007). Por lo tanto, tomando en cuenta ambos criterios mencionados, se sustenta que tener una muestra con 445 participantes para el presente estudio es un tamaño adecuado para realizar los análisis estadísticos correspondientes.

En la Tabla 4.1 se observan las frecuencias para cada momento de migración. Se encuentra que el $23 \%$ de la muestra total ha migrado de una zona rural a una urbana en algún momento entre los años 2003 y 2009. Del total de migrantes, la mitad de ellos se movilizó a áreas urbanas antes del 2006 y la otra mitad lo hizo antes del 2009. 
Tabla 4.1

Distribución de frecuencias de la muestra para según momento de migración

\begin{tabular}{lccc}
\hline Migración & Frecuencia & Porcent. (\%) & Acum. (\%) \\
\hline Migración temprana & 51 & 11.46 & 11.46 \\
Migración tardía & 51 & 11.46 & 22.92 \\
No migró & 343 & 77.08 & 100 \\
\hline Total & 445 & 100 & \\
\hline
\end{tabular}

El contexto geográfico en el que crece el niño es una de las principales variables del estudio, por ello se presentan en la Tabla 4.2 y Tabla 4.3 las características sociodemográficas de la muestra según el momento (o ausencia) de migración.

Se encuentra que la muestra se divide equitativamente respecto al sexo, a la lengua materna y a la ayuda que reciben los niños por parte de sus padres al hacer tareas. Un poco más de la mitad de los niños ha asistido a un centro de educación inicial y una cantidad similar suele leer por entretenimiento. La mayoría tiene madres con un nivel educativo inferior a la secundaria completa y, de la misma forma, es una minoría los que tienen más de cinco libros, sin contar textos escolares, en sus hogares. Todos los niños de la muestra, a excepción de tres, asisten a la escuela. Por otro lado, cabe señalar que en el 2009 la edad promedio de los niños es de 8 años (D.E. = 3.74 meses). Además, la muestra cuenta un índice de nivel socioeconómico promedio de .21 (DE = $0.13)$, lo que quiere decir que el promedio de los sujetos evaluados vive en condiciones de pobreza. El promedio de la relación de la talla respecto a la edad es de -1.67 (D.E. = 1.23), lo que quiere decir que los niños presentan una altura por debajo de lo que se espera para su edad. 
Tabla 4.2

Características demográficas de la muestra (variables dicotómicas)

\begin{tabular}{|c|c|c|c|c|c|c|c|c|c|c|c|c|c|}
\hline & & \multicolumn{3}{|c|}{ Migración temprana } & \multicolumn{3}{|c|}{ Migración tardía } & \multicolumn{3}{|c|}{ No migró } & \multicolumn{3}{|c|}{ Total } \\
\hline & & Frec. & $\begin{array}{l}\text { Porcent. } \\
(\%)\end{array}$ & $\begin{array}{l}\text { Acum. } \\
(\%)\end{array}$ & Frec. & $\begin{array}{l}\text { Porcent. } \\
(\%)\end{array}$ & $\begin{array}{l}\text { Acum. } \\
(\%)\end{array}$ & Frec. & $\begin{array}{l}\text { Porcent. } \\
(\%)\end{array}$ & $\begin{array}{l}\text { Acum. } \\
(\%)\end{array}$ & Frec. & $\begin{array}{l}\text { Porcent. } \\
(\%)\end{array}$ & $\begin{array}{l}\text { Acum. } \\
(\%)\end{array}$ \\
\hline \multirow{2}{*}{ Sexo } & Masculino & 22 & 43.14 & 43.14 & 24 & 47.06 & 47.06 & 168 & 48.98 & 48.98 & 214 & 48.09 & 48.09 \\
\hline & Femenino & 29 & 56.86 & 100 & 27 & 52.94 & 100 & 175 & 51.02 & 100 & 231 & 51.91 & 100 \\
\hline \multirow{2}{*}{$\begin{array}{l}\text { Educación de la } \\
\text { madre }\end{array}$} & Incompleta & 38 & 74.51 & 74.51 & 45 & 88.24 & 88.24 & 313 & 91.25 & 91.25 & 396 & 88.99 & 88.99 \\
\hline & Sec. completa & 13 & 25.49 & 100 & 6 & 11.76 & 100 & 30 & 8.75 & 100 & 49 & 11.01 & 100 \\
\hline \multirow{2}{*}{$\begin{array}{l}\text { Lengua materna } \\
\text { en el hogar }\end{array}$} & Castellano & 34 & 66.67 & 66.67 & 28 & 54.9 & 54.9 & 185 & 53.94 & 53.94 & 247 & 55.51 & 55.51 \\
\hline & Nativa & 17 & 33.33 & 100 & 23 & 45.1 & 100 & 158 & 46.06 & 100 & 198 & 44.49 & 100 \\
\hline \multirow{2}{*}{$\begin{array}{l}\text { Educación inicial } \\
\text { del niño }\end{array}$} & No & 11 & 21.57 & 21.57 & 18 & 35.29 & 35.29 & 149 & 43.44 & 43.44 & 178 & 40 & 40 \\
\hline & Sí & 40 & 78.43 & 100 & 33 & 64.71 & 100 & 194 & 56.56 & 100 & 267 & 60 & 100 \\
\hline \multirow{2}{*}{$\begin{array}{l}\text { Educación } \\
\text { primaria del niño }\end{array}$} & No & 0 & 0 & 0 & 2 & 3.92 & 3.92 & 1 & 0.29 & 0.29 & 3 & 0.67 & 0.67 \\
\hline & Sí & 51 & 100 & 100 & 49 & 96.08 & 100 & 342 & 99.71 & 100 & 442 & 99.33 & 100 \\
\hline \multirow{2}{*}{$\begin{array}{l}\text { Recibe ayuda en } \\
\text { tareas }\end{array}$} & No & 20 & 39.22 & 39.22 & 24 & 47.06 & 47.06 & 184 & 53.64 & 53.64 & 228 & 51.24 & 51.24 \\
\hline & Sí & 31 & 60.78 & 100 & 27 & 52.94 & 100 & 159 & 46.36 & 100 & 217 & 48.76 & 100 \\
\hline \multirow{2}{*}{$\begin{array}{l}\text { Lee por } \\
\text { entretenimiento }\end{array}$} & No & 20 & 39.22 & 39.22 & 16 & 31.37 & 31.37 & 120 & 34.99 & 34.99 & 156 & 35.06 & 35.06 \\
\hline & Sí & 31 & 60.78 & 100 & 35 & 68.63 & 100 & 223 & 65.01 & 100 & 289 & 64.94 & 100 \\
\hline \multirow{2}{*}{$\begin{array}{l}\text { Cantidad de libros } \\
\text { en casa }\end{array}$} & $\leq 5$ libros & 45 & 88.24 & 88.24 & 41 & 80.39 & 80.39 & 321 & 93.59 & 93.59 & 407 & 91.46 & 91.46 \\
\hline & $>5$ libros & 6 & 11.76 & 100 & 10 & 19.61 & 100 & 22 & 6.41 & 100 & 38 & 8.54 & 100 \\
\hline
\end{tabular}


Tabla 4.3

Características demográficas de la muestra (variables continuas)

\begin{tabular}{|c|c|c|c|c|c|c|c|c|c|c|c|c|c|c|c|c|c|c|c|c|}
\hline \multirow[b]{2}{*}{ Variable } & \multicolumn{5}{|c|}{ Migración temprana } & \multicolumn{5}{|c|}{ Migración tardía } & \multicolumn{5}{|c|}{ No migró } & \multicolumn{5}{|c|}{ Total } \\
\hline & $\mathrm{N}$ & $\mathrm{M}$ & D.E. & Mín. & Máx. & $\mathrm{N}$ & $\mathrm{M}$ & D.E. & Mín. & Máx. & $\mathrm{N}$ & $\mathrm{M}$ & D.E. & Mín. & Máx. & $\mathrm{N}$ & $\mathrm{M}$ & D.E. & Mín. & Máx. \\
\hline $\begin{array}{l}\text { Índice } \\
\text { socioeconómico }\end{array}$ & 51 & 0.24 & 0.16 & 0.01 & 0.84 & 51 & 0.23 & 0.13 & 0.00 & 0.68 & 343 & 0.20 & 0.12 & 0.00 & 0.67 & 445 & 0.21 & 0.13 & 0.00 & 0.84 \\
\hline Talla para la edad & 51 & -1.14 & 1.40 & -4.04 & 4.79 & 51 & -1.55 & 1.18 & -3.83 & 0.68 & 343 & -1.77 & 1.19 & -4.95 & 2.94 & 445 & -1.67 & 1.23 & -4.95 & 4.79 \\
\hline Edad del niño (meses) & 51 & 94.90 & 3.96 & 85.00 & 101.00 & 51 & 95.27 & 3.67 & 89.00 & 102.00 & 343 & 95.11 & 3.73 & 89.00 & 102.00 & 445 & 95.11 & 3.74 & 85.00 & 102.00 \\
\hline
\end{tabular}




\subsection{Técnicas de recolección de información}

Para el presente estudio se utiliza el Test de Vocabulario en Imágenes Peabody: Adaptación Hispanoamericana ([TVIP] Dunn et al., 1986), aplicado como parte del estudio Niños del Milenio, para hallar el nivel del desarrollo del vocabulario receptivo. Este es la adaptación hispanoamericana del Peabody Picture Vocabulary Test-Revised, el cual fue elaborado por Lloyd Dunn y Leota Dunn en 1981. La prueba tiene como principal objetivo medir la amplitud de vocabulario receptivo o auditivo adquirido en personas desde los 2.5 hasta los 18 años de edad (Dunn et al., 1986).

La prueba consta de 125 ítems y consiste en identificar la imagen que expresa la palabra estímulo. El examinador presenta al evaluado varias cartillas, cada una con cuatro imágenes, al mismo tiempo que enuncia la palabra estímulo. El evaluado debe señalar cuál de las figuras representa el significado de la palabra oída y el evaluador registra la respuesta en una plantilla. La administración de la prueba requiere identificar el "margen crítico" de ítems, el cual varía en función a cada sujeto y se delimita por el ítem base (límite inferior) y por el ítem tope (límite superior). El punto de inicio de la administración de la prueba varía dependiendo de la edad cronológica de cada niño, el ítem base corresponde a las ocho respuestas correctas consecutivas más altas y el ítem tope corresponde a las ocho respuestas consecutivas más bajas que contengan seis errores. El puntaje se obtiene al restar al ítem tope la cantidad de errores contenidas entre el "rango crítico" del niño (Dunn et al., 1986).

En cuanto a las evidencias psicométricas evaluadas para los datos recogidos en el estudio Niños del Milenio, se aportan evidencias de confiabilidad y validez (Cueto y León, 2012). En primer lugar, se muestran evidencias de confiabilidad de los puntajes directos en el TVIP para los participantes del estudio mediante el coeficiente de Alfa de Cronbach, este obtuvo un valor de $\alpha=.97, \mathrm{EEM}=2.9$ (Cueto y León, 2012). Asimismo, se convirtieron las puntuaciones directas a puntajes rasch de un parámetro, de modo que se permita poner sobre una misma escala la dificultad del ítem y las habilidades del evaluado $(\mathrm{M}=300, \mathrm{DE}=15)$. El índice de confiabilidad para los puntajes rasch también se muestra alto, con un valor de $.95, \mathrm{EEM}=3.4$ (Cueto y León, 2012). Con esto se demuestra que existe consistencia entre los resultados de los ítems aplicados, dada la alta correlación entre los ítems del test. 
En segundo lugar, se encuentran evidencias de validez de los resultados para este estudio mediante dos fuentes. Una de ellas es la estructura interna, que hace referencia a la homogeneidad de los ítems para indicar la unidimensionalidad de la prueba (American Educational Research Association [AERA], American Psychological Association [APA], y National Council on Measurement in Education [NCME], 2014). Para el análisis rasch, se toma un supuesto de unidimensionalidad de los ítems, el cual luego se corrobora mediante los índices de infit y outfit a partir de los resultados obtenidos para cada ítem. Estos índices reportan el comportamiento de cada uno de los ítems respecto a la prueba, confirmando un adecuado ajuste al modelo en las pruebas aplicadas. Los índices de infit y outfit toman valores entre 0.5 y 1.5 para todos los ítems, ofreciendo así evidencias de validez para los puntajes del TVIP en esta muestra (Cueto y León, 2012).

La segunda fuente corresponde a las evidencias de validez basadas en relación a otras variables (AERA, APA, y NCME, 2014). Los resultados en el TVIP obtenidos se correlacionaron con otras variables del estudio que, en literatura internacional y nacional, han comprobado guardar relación con el desarrollo del vocabulario (Cueto y León, 2012). Así, se encontró que tanto las puntuaciones directas como las rasch para el TVIP se correlacionan de manera estadísticamente significativa con resultados en prueba de lectura $(r=.57, p<.001)$ y de matemática $(r=.62, p<.001)$, también se manifiesta una correlación significativa del desarrollo del vocabulario con el índice de nivel socio-económico $(r=.54, p<.001)$ y con la educación de la madre $(r=.43, p<$ .001), entre otros; todas estas, de acuerdo con lo esperado (Cueto y León, 2012).

\subsection{Procedimiento de recolección de datos}

Los instrumentos fueron aplicados individualmente por los trabajadores de campo del estudio Niños del Milenio, quienes fueron debidamente capacitados para ello. Se compraron a la editorial los suficientes ejemplares del TVIP (Cueto y León, 2012) y se buscó que la administración del instrumento se diera en condiciones con suficiente luz (de preferencia luz natural) y silencio, de modo que factores externos no perjudiquen el rendimiento de los niños. Se contó con el consentimiento de los padres antes de aplicar los instrumentos. 
Los datos del estudio se encuentran disponibles para la comunidad académica y son administrados mediante el Servicio de Base de Datos del Reino Unido (UK Data Service). Para acceder a ellos, la autora de la presente investigación se registró en el "UK Data Archive" como estudiante de la Universidad de Lima, justificando el uso de los datos para la tesis de bachiller; esto se hizo a través del formulario web disponible en: www.data-archive.ac.uk/sign-up/credentials-application\#sthash.Mxhh9ypn.dpuf. El sistema envió un mensaje de confirmación, indicando un usuario y contraseña, además de las instrucciones, para poder ingresar a los datos de Niños del Milenio. Se aceptó el consentimiento de licencia de usuario, que se encuentra en el Anexo 4 del presente documento, y con esto quedó aprobada la descarga de las bases de datos. 


\section{CAPÍTULO V: RESULTADOS}

\subsection{Estrategias de análisis de datos}

Se hallaron las medidas de tendencia central (media, desviación estándar), distribución de normalidad de los puntajes rasch y análisis de varianza para describir la muestra y los datos que esta presenta. Luego, se llevó a cabo un análisis correlación entre las variables con diferentes coeficientes de correlación, dependiendo si las variables son dicotómicas o continuas (Field, 2009). Este análisis permitió identificar qué variables guardan una relación estadísticamente significativa con el desarrollo del vocabulario y, por lo tanto, deberían ser analizadas mediante una regresión lineal múltiple. De este modo, se pudo hallar el grado en el que la migración, y otras variables de control, predicen el desarrollo del vocabulario (Field, 2009). Es decir, a partir del análisis de regresión lineal múltiple se logró identificar cuánto varía el desarrollo del vocabulario en función de la migración. Se utilizó el método de regresión de entrada directa (forced entry), en el que se eligen las variables independientes con base en la literatura y experiencias previas, y se ingresan todas de manera simultánea, sin un orden particular (Field, 2009). Según Studenmund y Cassidy (citados en Field, 2009), este método de regresión es el más apropiado para testear la teoría de un estudio y su carácter aleatorio permite replicar el modelo. También se realizó un análisis de colinealidad entre las variables de control para confirmar que no guardan relación entre ellas, lo que podría afectar el modelo. En la Tabla 5.1 se describen las estrategias de análisis a utilizar, con base en la teoría explicada por Field (2009). 
Tabla 5.1

Estrategias de análisis

\begin{tabular}{|c|c|c|}
\hline Análisis de datos & Estadístico & Objetivo \\
\hline $\begin{array}{l}\text { Medidas de tendencia } \\
\text { central }\end{array}$ & $\begin{array}{l}\text { Media aritmética } \\
\text { Desviación estándar }\end{array}$ & $\begin{array}{l}\text { Describir la muestra en función a sus puntajes de } \\
\text { vocabulario }\end{array}$ \\
\hline $\begin{array}{l}\text { Distribución de } \\
\text { normalidad }\end{array}$ & $\begin{array}{l}\text { Coeficientes de } \\
\text { asimetría y curtosis } \\
\text { Test D’Agostino }\end{array}$ & $\begin{array}{l}\text { Identificar si se trata de una distribución } \\
\text { paramétrica }\end{array}$ \\
\hline Análisis de varianza & $\begin{array}{l}\text { ANOVA por rango de } \\
\text { Kruskal-Wallis, U de } \\
\text { Mann Whitney }\end{array}$ & $\begin{array}{l}\text { Examinar si existen diferencias estadísticamente } \\
\text { significativas entre los grupos de migración y el } \\
\text { desarrollo del vocabulario }\end{array}$ \\
\hline \multirow[t]{2}{*}{$\begin{array}{l}\text { Análisis de correlación } \\
\text { entre las variables }\end{array}$} & Coeficiente tetracórico & $\begin{array}{l}\text { Examinar la correlación entre dos variables } \\
\text { dicotómicas }\end{array}$ \\
\hline & $\begin{array}{l}\text { Coeficiente biserial } \\
\text { puntual } \\
\text { Coeficiente de Pearson }\end{array}$ & $\begin{array}{l}\text { Examinar la correlación entre una variable } \\
\text { dicotómica y una continua } \\
\text { Examinar la correlación entre dos variables } \\
\text { continuas }\end{array}$ \\
\hline $\begin{array}{l}\text { Análisis de regresión } \\
\text { lineal múltiple }\end{array}$ & Betas estandarizados & $\begin{array}{l}\text { Examinar qué porcentaje de la varianza explica } \\
\text { el modelo y el valor predictor de cada variable } \\
\text { sobre la variable dependiente }\end{array}$ \\
\hline Análisis de colinealidad & $\begin{array}{l}\text { Factor de inflación de } \\
\text { la varianza }\end{array}$ & $\begin{array}{l}\text { Examinar si alguna variable predictora guarda } \\
\text { una fuerte relación lineal con otro predictor }\end{array}$ \\
\hline
\end{tabular}

\subsection{Presentación de resultados}

Respecto a los resultados descriptivos de la variable dependiente, se observa que para los 445 niños que conforman la muestra, los puntajes referidos al desarrollo del vocabulario oscilan entre 243 y 342 , teniendo en promedio 296.83 puntos rasch (D.E. $=12.57)$. Tomando en cuenta que estos resultados no cuentan con baremos adaptados para la población, se analizarán comparándolos entre los distintos grupos de la muestra.

Se analiza si esta variable presenta una distribución normal. En el histograma de la Figura 5.1 se encuentra que no se cumple este criterio, así como en la Tabla 5.2. En esta última, se evidencia mediante el test de normalidad de D'Agostino (Stata, 2013) que los puntajes de la muestra para el TVIP están distribuidos de manera asimétrica alrededor de la mediana de los puntajes, ya que tanto los coeficientes de asimetría y de curtosis igualan $0.00(p<.005)$, rechazando así la hipótesis nula que hace referencia a una distribución normal. Por ello, se puede afirmar que se está trabajando con una distribución no paramétrica de los resultados. 
Figura 5.1

Distribución de puntajes rasch para el TVIP (desarrollo de vocabulario receptivo)

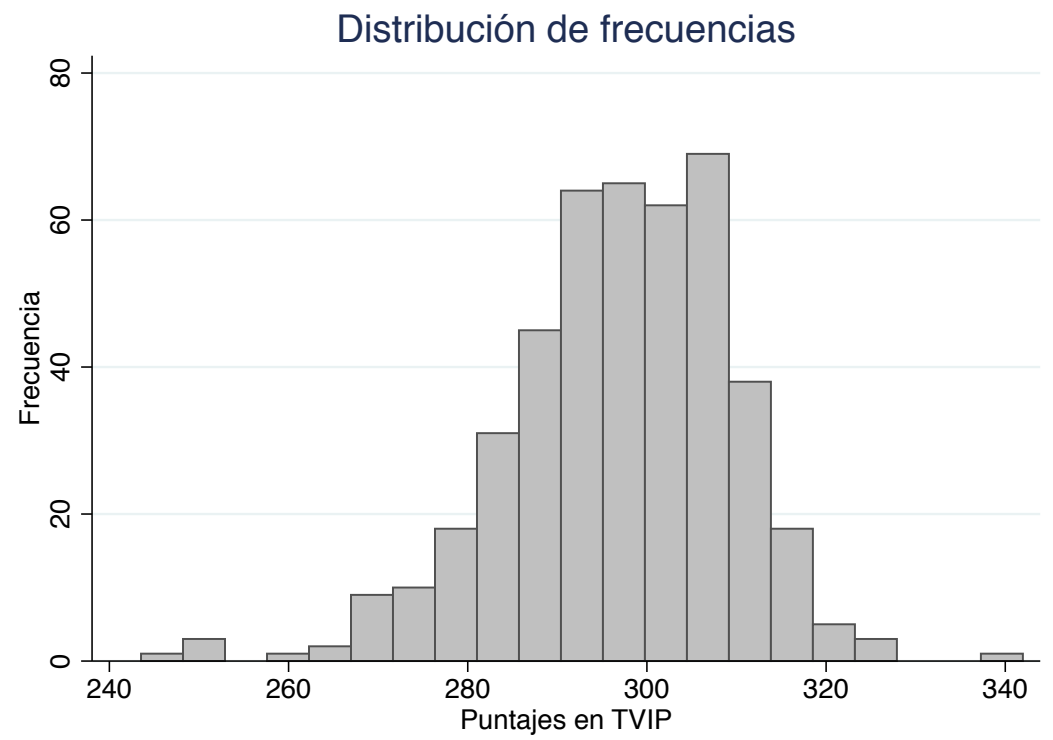

Tabla 5.2

Test de normalidad de asimetría y curtosis (Test de D'Agostino)

\begin{tabular}{llllll}
\hline Variable & Obs & Pr(Asimetría) & Pr(Curtosis) & adj chi ${ }^{2}$ & Prob $>$ chi2 \\
\hline Pje. Rasch TVIP & 445 & .000 & $.0002^{* *}$ & $31.17^{* *}$ & .000 \\
\hline Nota: $\mathrm{M}=296.83$ (D.E. 12.56); ${ }^{*} \mathrm{p}<.05^{* *} \mathrm{p}<.01^{* *} \mathrm{p}<.005$ & &
\end{tabular}

En la Tabla 5.3 se describen los puntajes rasch para el TVIP por cada grupo en el que se divide la muestra (los que migraron antes de sus cinco años de edad, los que migraron antes de sus ocho años de edad y los que no migraron). Para verificar que existe una diferencia estadística significativa entre los grupos se realiza el análisis de varianza de Kruskal-Wallis, el cual se utiliza para análisis no-paramétricos (Field, 2009). En la Tabla 5.4 se observa que existe una diferenciación estadísticamente significativa entre por lo menos dos de las medias de los grupos $\left(\mathrm{x}^{2}=35.11, p<\right.$ .0001). Mediante el análisis de U de Mann Whitney se realizaron las comparaciones entre pares. Se encuentra que existen diferencias estadísticamente significativas 
pequeñas entre los que no migraron y los que migraron tardíamente, a favor de estos últimos, $\mathrm{Z}_{\mathrm{u}}(\mathrm{gl})=3.77, p=.0002, r=.18$. También se observa que los que no migraron y los que lo hicieron tempranamente se diferencian estadísticamente y son estos últimos los que tienen mayores puntajes, $\mathrm{Z}_{\mathrm{u}}(\mathrm{gl})=5.01, p=.00, r=.24$. En cuanto a la comparación de medias correspondientes a los dos grupos migratorios (migración temprana y tardía) se encuentra que la diferencia, en la que la migración temprana tiene una ligera ventaja sobre la migración tardía, no es estadísticamente significativa y es muy pequeña $\mathrm{Z}_{\mathrm{u}}(\mathrm{gl})=1.24, p=.22, r=.06$. Se demuestra que sí existe una diferencia en cuanto al puntaje en el TVIP entre los que migraron y los que no migraron; entre los grupos migrantes se observa una diferencia muy ligera que no es estadísticamente significativa, esto es lo que se espera dadas las características de las variables estudiadas. Específicamente, se observa que los niños que no migraron obtuvieron la media de rangos más baja, mientras que los que migraron tempranamente obtuvieron el puntaje más alto.

Tabla 5.3

Descripción de puntajes rasch para el TVIP según momento de migración

\begin{tabular}{|c|c|c|c|c|c|c|c|c|c|}
\hline \multirow[b]{2}{*}{ Variable } & \multicolumn{3}{|c|}{ Migración temprana } & \multicolumn{3}{|c|}{ Migración tardía } & \multicolumn{3}{|c|}{ No migró } \\
\hline & $\mathrm{N}$ & $\mathrm{M}$ & D.E. & $\mathrm{N}$ & $\mathrm{M}$ & D.E. & $\mathrm{N}$ & $\mathrm{M}$ & D.E. \\
\hline TVIP & 51 & 303.99 & 10.10 & 51 & 301.09 & 11.98 & 343 & 295.13 & 12.49 \\
\hline
\end{tabular}


Tabla 5.4

Análisis de varianza Kruskal-Wallis

\begin{tabular}{llll}
\hline & Observaciones & Media de rangos & Suma ranqueada \\
\hline Migración temprana & 51 & 301.13 & 15357.50 \\
Migración tardía & 51 & 275.43 & 14047.00 \\
No migró & 344 & 203.00 & 69830.50 \\
\hline & & & \\
Chi-cuadrado $=$ & 35.114 & & \\
gl $=$ & 2 & & \\
Probabilidad $=$ & .0001 & &
\end{tabular}

A continuación, se realiza el análisis de correlación entre las variables, el cual se presenta en la Tabla 5.5. Cabe señalar que se realizaron diferentes análisis de correlación según el tipo de variables. Así, para la relación entre dos variables dicotómicas se utilizó el coeficiente tetracórico $\left(\mathrm{r}_{\mathrm{t}}\right)$, para la relación entre una variable dicotómica y una continua se analizó con el coeficiente biserial puntual $\left(\mathrm{r}_{\mathrm{pb}}\right)$, y la correlación entre dos variables continuas se reporta mediante el coeficiente $r$ de Pearson (Field, 2009).

Se observa que las únicas variables que no presentan una correlación significativa con los puntajes rasch para el TVIP son sexo, educación escolar del niño y la cantidad de libros que se tienen en el hogar. Destaca que la migración, tanto temprana $\left(\mathrm{r}_{\mathrm{pb}}=.20, p<.05\right)$ como tardía $\left(\mathrm{r}_{\mathrm{pb}}=.12, p<.05\right)$, tiene una correlación significativa y positiva con el TVIP. Además, se encuentra que ninguna de las correlaciones significativas entre las variables independientes es sustancial. La única excepción es la correlación entre migración temprana y tardía $(\mathrm{r}=-1.00, p<.01)$, que se da por ser variables que se excluyen mutuamente. Este análisis permite excluir del modelo de regresión lineal múltiple a las variables de sexo, educación primaria del niño y cantidad de libros, por no evidenciar relación estadísticamente significativa con la variable de interés. 


\section{Tabla 5.5}

Matriz de correlaciones entre las variables $(N=445)$

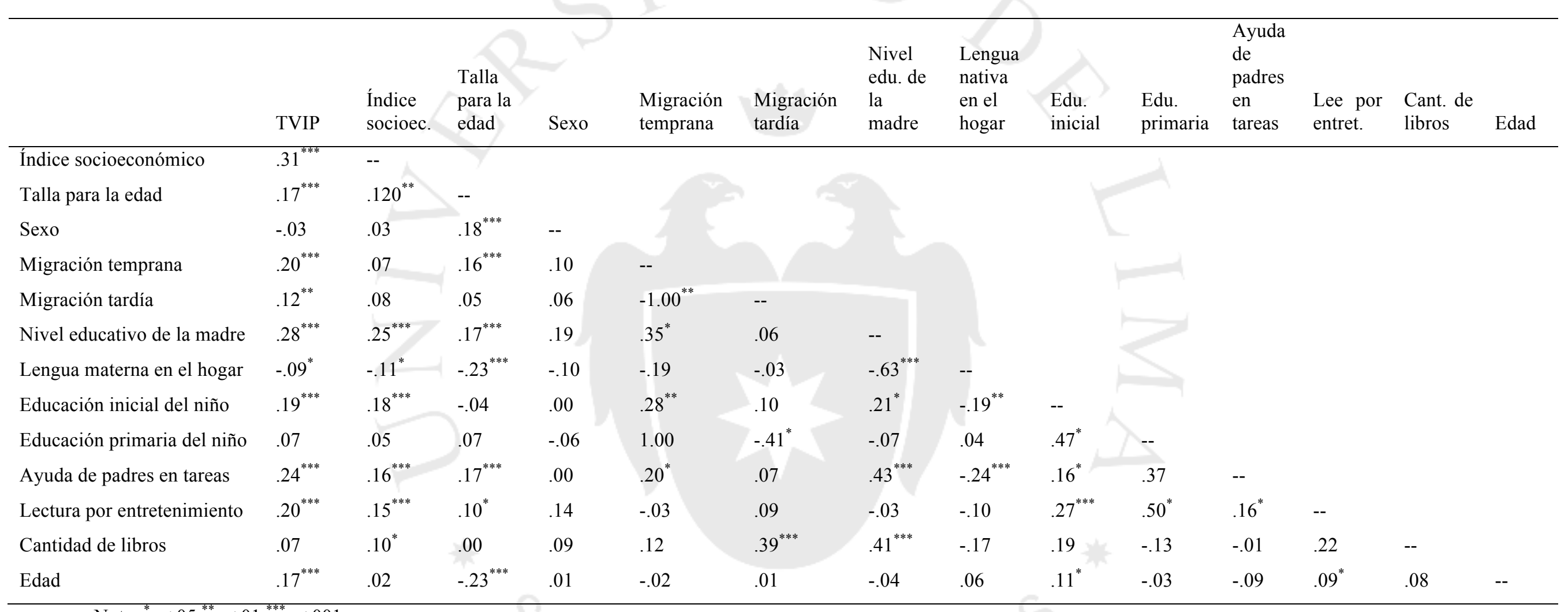

Nota: ${ }^{*} \mathrm{p}<.05{ }^{* *} \mathrm{p}<.01{ }^{* * *} \mathrm{p}<.001$ 
Finalmente, se lleva a cabo el análisis de regresión lineal múltiple en el cual se busca identificar el rol predictor de cada una de las variables independientes sobre el puntaje referido al desarrollo del vocabulario receptivo. La Tabla 5.6 revela que el modelo explica el $27 \%$ de la varianza del puntaje TVIP, con un ajuste estadístico significativo al modelo $(p<.001)$. Se encuentra un tamaño grande del efecto, $\mathrm{f}^{2}=.37$, (Cohen, 1992), lo que quiere decir que existe una fuerza de relación alta y relevante entre las variables estudiadas. También se evalúa la potencia estadística, es decir, la probabilidad de no cometer un error de tipo II, que representa la importancia estadística del hallazgo de la investigación. Los análisis realizados sugieren que la potencia estadística es muy alta $(1-\beta=.999)$, es decir que es mínima la probabilidad de no rechazar la hipótesis nula cuando esta es falsa con los datos estudiados.

A partir de estos análisis, se puede señalar que el modelo de regresión utilizado presenta un valor significativo y dentro de lo esperado en el campo de las ciencias sociales, para explicar la varianza en la amplitud del vocabulario con una potencia de predicción moderada (Keith, 2015; Field, 2009); es decir, los análisis cuentan con las condiciones óptimas. Se utilizaron estadísticos de robustez en el modelo de regresión, es decir que como parte del análisis se pesaron las variables en función a su varianza, de forma que se minimiza el efecto de aquellas que están más alejadas de la media (Stata, 2013). Al contar con errores estándar robustos, se permite garantizar que los resultados, a pesar de no tener una distribución normal, mantienen su potencia y por lo tanto no se presentaría mayor discrepancia en los hallazgos (Field, 2009).

Respecto al rol predictor de cada variable independiente sobre la variable dependiente, se muestra que todas son estadísticamente significativas excepto educación inicial $(\beta=.07, p>.05)$ y lengua materna en el hogar $(\beta=.03, p>.05)$. Si bien las variables de interés resultan significativas, se encuentra que las variables de control explican una mayor proporción de la varianza. Se evidencia que la edad del niño $(\beta=.20, p<.001)$ y el nivel socioeconómico $(\beta=.18, p<.001)$ son los predictores más fuertes sobre la variable dependiente, seguidos por el nivel educativo de la madre $(\beta=$ $.17, p<.001)$. Esto quiere decir que si la madre alcanza la secundaria completa o un nivel educativo superior, el puntaje en el vocabulario aumentará en .17 desviaciones estándar o en 6.87 puntos rasch en el TVIP.

Además, se comprueba que las variables de migración son estadísticamente significativas, teniendo la migración temprana $(\beta=.15, p<.001)$ una mayor fuerza que 
la migración tardía $(\beta=.11, p<.01)$ para predecir el desarrollo del vocabulario receptivo a los ocho años de edad. Así, si el niño migra a una zona urbana antes de sus cinco años de edad, la amplitud de su vocabulario aumentará en .15 desviaciones estándar del puntaje rasch del TVIP o en 5.81 puntos rasch, pero si migra entre sus cinco y ocho años de edad, el puntaje rasch del TVIP solo aumentará en 0.11 desviaciones estándar, que significan 4.34 puntos rasch. También se observa que el recibir ayuda en las tareas escolares por parte de sus padres $(\beta=.14, p<.001)$, leer por entretenimiento $(\beta=.13, p<.001)$ y la talla para la edad $(\beta=.12, p<.01)$ tienen un valor predictor moderado sobre el desarrollo del vocabulario receptivo.

Tabla 5.6

Variables predictoras del desarrollo del vocabulario receptivo

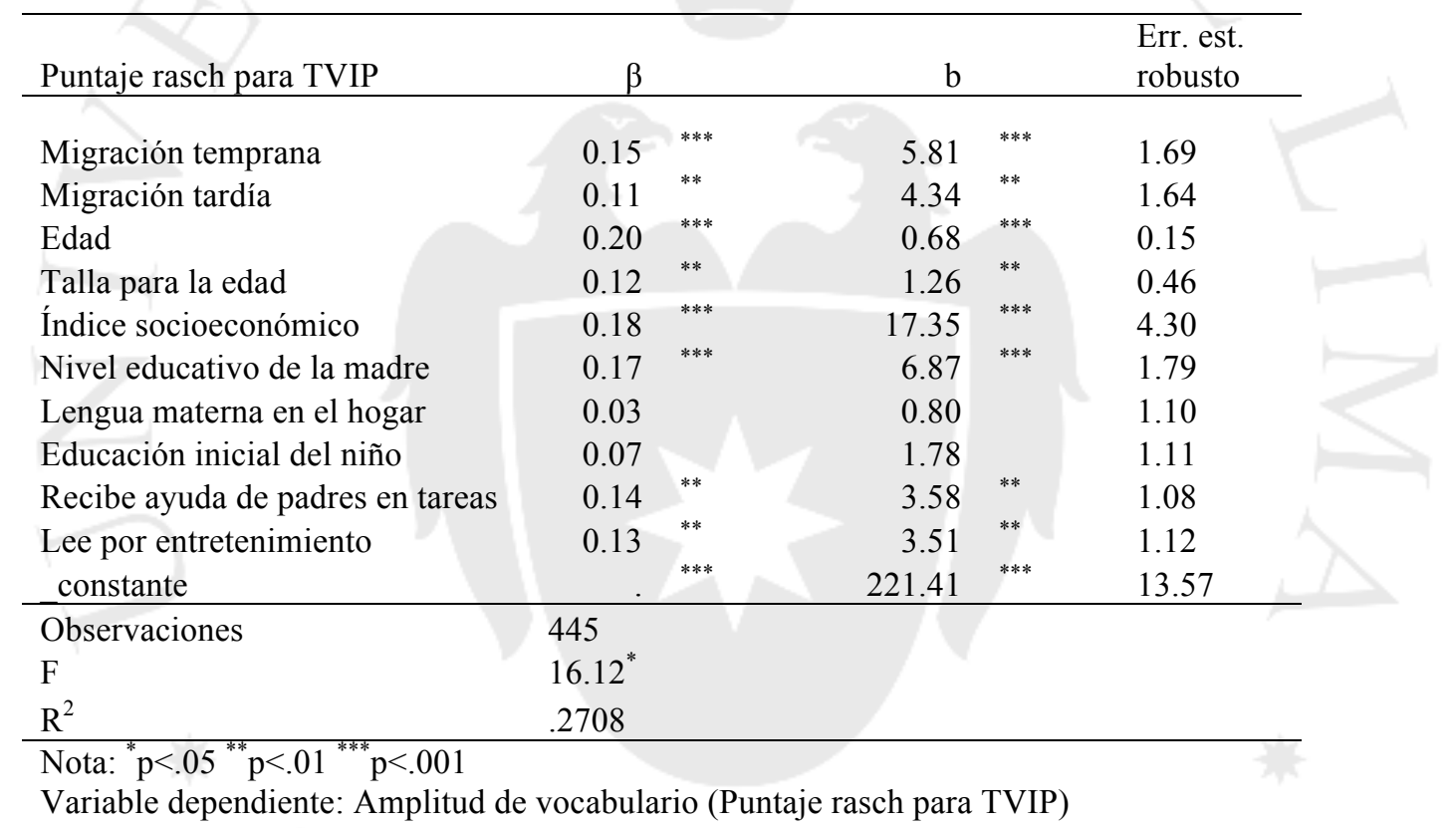

Con el fin de verificar que no existen problemas de colinealidad, es decir que un predictor no tenga una fuerte relación lineal con otro predictor, se realiza el análisis del factor de inflación de la varianza (FIV), mostrado en la Tabla 5.7 (Keith, 2015). Teniendo una media FIV de 1.12 se comprueba que ninguna de las variables independientes está explicada por otra de las mismas, es decir que cada variable afecta independientemente a la varianza del desarrollo de vocabulario receptivo. También se puede observar que la tolerancia (1/FIV) para todos los casos es mayor a 0.2 , lo cual confirma la ausencia de problemas de colinealidad (Keith, 2015). 
Tabla 5.7

Análisis de colinealidad

\begin{tabular}{lll}
\hline Variable & FIV & $1 /$ FIV \\
\hline Talla para la edad & 1.21 & 0.82 \\
Nivel educativo de la madre & 1.19 & 0.84 \\
Nivel socioeconómico & 1.14 & 0.88 \\
Lengua materna en el hogar & 1.13 & 0.88 \\
Educación inicial del niño & 1.12 & 0.89 \\
Edad & 1.11 & 0.90 \\
Recibe ayuda de padres en tareas & 1.10 & 0.91 \\
Migración temprana & 1.10 & 0.91 \\
Lee por entretenimiento & 1.07 & 0.93 \\
Migración tardía & 1.03 & 0.97 \\
\hline Media FVI & 1.12 & \\
\hline
\end{tabular}




\section{CAPÍTULO VI: DISCUSIÓN}

En la presente investigación se buscó identificar el rol predictor de la migración ruralurbano sobre la amplitud del vocabulario, en una población de niños de 8 años de edad, que durante sus primeros meses de vida se encontraban viviendo en áreas rurales. Para ello, se llevó a cabo un análisis de regresión lineal que incluyó como variables de interés la migración temprana y la tardía, ya que no se encuentran estudios previos que se enfoquen en el rol predictor de la migración sobre el desarrollo del niño. Además de las variables de interés, se toman en cuenta otras variables de control, que en estudios previos se han evidenciado como asociadas a la amplitud del vocabulario (sexo, edad, índice socioeconómico, educación de la madre, talla para la edad, lengua materna en el hogar, educación inicial, educación primaria, cantidad de libros en el hogar, lectura por entretenimiento y el recibir ayuda en las tareas escolares).

Los resultados obtenidos en el análisis explicativo coinciden con la literatura revisada y permiten rechazar además la hipótesis nula del presente estudio. Se observa, en primer lugar, que tanto la migración temprana como la tardía son significativas en predecir mejores resultados en vocabulario receptivo. Si bien es conocida la brecha en el desempeño educativo en el Perú entre los niños que viven en zonas urbanas y en rurales, este estudio permite conocer que la movilidad geográfica interviene también en el rendimiento cognitivo. De acuerdo con la teoría ecológica de Bronfenbrenner (1987) y la evidencia hallada en algunos estudios (Brownell et al., 2016; Mastin y Vogt, 2015; Romay et al., 2012), se comprueba el rol fundamental que tiene el contexto rural y el cambio de este sobre el desarrollo lingüístico y cognitivo del niño.

En particular, se observa que la migración temprana tiene una mayor fuerza de predicción respecto a la tardía. La migración antes de los 5 años de edad es uno de los predictores estadísticamente más significativos (por alcanzar un elevado peso en el coeficiente $\beta$ ) respecto a la amplitud del vocabulario a los 8 años de edad, además de la edad, el índice socioeconómico y la educación de la madre. Esto se explica teniendo en cuenta que la fase crítica del desarrollo del vocabulario ocurre en los primeros años de vida (Alexander y Uccelli, 2010; Santrock, 2007); entonces, se podría deducir que si el niño está expuesto a mejores condiciones contextuales en sus primeros años de vida (que coinciden con la migración temprana, la cual se estima entre el primer y quinto 
año de edad), tendrá mayores probabilidades de desarrollar un vocabulario más amplio frente a aquellos que permanecieron en contextos rurales en esta etapa de su desarrollo. El cambio de contexto influenciará en las relaciones sociales que mantengan los niños, tal como lo mencionan Romay et al. (2012), y estas interacciones, sobre su desarrollo lingüístico.

La migración tardía manifiesta igualmente un rol predictor sobre el desarrollo de vocabulario receptivo, aunque menor que la migración temprana, e incluso menor que otros factores asociados. De esto, se deduce que los que tienen menos posibilidades de contar con un vocabulario más amplio son aquellos niños que permanecen en áreas rurales por más tiempo. Entre los distintos factores de riesgo que podrían explicar una menor estimulación cognitiva y lingüística en áreas rurales de un país latinoamericano como Perú, se incluirían el poco acceso a servicios básicos (Cueto et al., 2014), los bajos ingresos no solo de la familia del niño sino también la de sus vecinos así como su nivel socioeconómico (Brownell et al., 2016), y las escasas relaciones interpersonales por la dispersión de las viviendas (Romay et al., 2012).

Por otro lado, se encuentra que el nivel socioeconómico y la educación de la madre, condiciones que están sujetas al hogar en las que nace el niño, son los mayores predictores del desarrollo del vocabulario, lo cual es consistente con los distintos estudios que se han realizado en Latinoamérica evaluando el desarrollo infantil (Coddington et al., 2014; Cueto et al., 2012; Cueto et al., 2016; Paxson y Schady, 2007; Rubio-Codina et al., 2013; Schady et al., 2014; Verdisco et al., 2015).

Otras variables predictora del desarrollo del vocabulario es la participación de los padres del niño en la realización de sus tareas escolares y el hábito del niño de leer por entretenimiento. Su influencia sobre el desarrollo del vocabulario se entiende al estar relacionada con la estimulación cognitiva y/o lingüística que se lleva a cabo en este tipo de interacciones padre/madre-hijo y al leer un libro por iniciativa propia; estudios como el de Dezcallar et al. (2014), Takeuchi et al. (2016) y Verdisco et al. (2015) han comprobado la importancia de este tipo de espacios para el desarrollo infantil, en particular para el cognitivo y comunicacional.

Por otro lado, se muestra que los factores individuales de los niños tienen también un rol predictor significativo; uno de ellos es la talla en relación a la edad. Estos resultados son consistentes con experiencias previas, que demuestran que los 
factores biomédicos tienen un rol predictor sobre el desarrollo del niño aunque es secundario ante la influencia del nivel socioeconómico y del ambiente (Rubio-Codina et al., 2013).

También se ha comprobado que en la actualidad, frente a lo que se demostraba en décadas anteriores, el sexo no guarda una relación estadísticamente significativa con el desarrollo cognitivo ni de vocabulario (Cueto et al., 2014); en el presente estudio tampoco se muestra relacionado al desarrollo de vocabulario.

Sin embargo, se encuentra que la lengua materna en el hogar tiene una correlación significativa muy baja con la variable dependiente, y no resulta significativa como predictor de la amplitud del vocabulario, lo cual contradice estudios como el de Cueto et al. (2014). Los niños que tienen una lengua indígena en el hogar muestran puntajes similares en el TVIP al de los castellanohablantes. Esto podría explicarse al tener en cuenta las características de la muestra, pues a todos los niños del estudio Niños del Milenio se les ofreció la posibilidad de rendir el TVIP en castellano o en quechua, según su preferencia. Se puede suponer que aquellos que tienen mayor dominio del quechua (frente al castellano) optaron por la prueba en dicha lengua. Los que tomaron esta elección fueron excluidos de la muestra pues solo se analizaron los resultados del TVIP en castellano. Así, una posible explicación es que los participantes de la presente investigación que tienen como lengua materna una indígena, tienen un suficiente dominio del castellano y se sienten más cómodos respondiendo la prueba en dicha lengua.

De la misma manera, se encuentra que para la muestra del estudio la asistencia a un centro de educación inicial no es estadísticamente significativa en predecir la amplitud del vocabulario a los 8 años de edad, contrario a lo que se había encontrado en otros estudios (Cueto et al., 2016; Rubio-Codina et al., 2013). Resulta importante explorar con mayor detenimiento las características de los centros pre-escolares en futuros estudios que se enfoquen en contextos rurales. Una posible explicación podría relacionarse con la baja calidad de los servicios que ofrecen estos centros educativos como estimulación cognitiva en poblaciones rurales.

Al observar la predicción de las distintas variables que resultaron estadísticamente significativas respecto al desarrollo del vocabulario, se encuentra cierta consistencia con la teoría ecológica de Bronfenbrenner (1897). La variable con 
mayor predicción sobre la amplitud del vocabulario es la edad, una variable individual. Las variables que corresponden al hogar en el que nace el niño y las relaciones que se dan en este, lo que Bronfenbrenner (1987) categorizaba dentro del microsistema, son el índice socioeconómico y educación de la madre, que siguiendo a la edad son las que mayor predicción estadística ejercen sobre el desarrollo del vocabulario. Como parte del mesosistema se incluirían las interacciones de los padres con sus hijos al ayudarlos a hacer su tarea y los hábitos del niño de leer por entretenimiento, dado que son actividades en las que interactúan el niño, el hogar y el espacio académico. Finalmente, la migración se ubicaría entre el exosistema y el macrosistema, espacios en los que se incluyen las características de la localidad, la influencia de los medios de comunicación, las tradiciones culturales, entre otros. Como se muestra en la imagen del Anexo 1, el orden de los coeficientes de las variables predictoras coincide con la proximidad de los sistemas hacia el individuo, que describe Bronfenbrenner (1987); para la mayoría de variables se cumple que las de mayor proximidad al individuo presentan una mayor fuerza de predicción sobre la amplitud del vocabulario.

Si bien todos estos datos ofrecen elementos para formular una explicación de los factores asociados al desarrollo del vocabulario receptivo, deben tomarse con cautela pues la muestra no es representativa de toda la población peruana. Los hallazgos podrán generalizarse solo a muestras de niños que nacen en áreas rurales, ya que el desarrollo de los niños en áreas urbanas podría diferenciarse significativamente por las variables contextuales ante las que están expuestos en los primeros meses de vida. Debe considerarse además, que los resultados se limitan a reflejar principalmente la realidad de niños castellanohablantes o niños que dominan el castellano tanto como su lengua nativa. También es importante notar que la versión aplicada del TVIP (1986) no es la más reciente, pero se utilizó dicha versión debido a las condiciones del estudio Niños del Milenio (cuando este comenzó aún no se había publicado la última versión del TVIP 2006) y no ocasionó ningún inconveniente en cuanto las evidencias de confiabilidad y validez de los resultados.

Sin embargo, no solo se valora el alto potencial estadístico del estudio sino también el tamaño del efecto grande encontrado, el cual es consiste con investigaciones previas y resalta la importancia que tienen los factores contextuales en el desarrollo del vocabulario receptivo, para poder tomar decisiones prácticas al respecto. 
La presente investigación aporta en la identificación de los factores asociados al desarrollo del vocabulario desde sus primeros meses de vida, incluyendo como una variable predictora el rol del área geográfica en la que crecen los niños. Al evidenciar que la migración hacia áreas urbanas predice un mejor rendimiento en el vocabulario, no se pretende destacar las ventajas de la migración. Por el contrario, se busca poner la atención sobre dos realidades: (1) los cambios cognitivos y académicos a los que se ven expuestos los niños migrantes y (2) el contexto geográfico como un factor que puede mejorar sus condiciones, pues no está sujeto a características intrínsecas del niño ni al hogar en el que nace. El contexto geográfico de crecimiento se trata de una variable que engloba las oportunidades que el niño encuentra en su medio (como los servicios básicos, espacios de recreación, calidad educativa, entre otros). Estas están sujetas al cambio mediante intervenciones a largo plazo y son responsabilidad tanto de la sociedad civil como del Estado.

Es de especial importancia conocer los cambios psicoeducativos que ocurren en los niños migrantes para poder tomar acciones al respecto; por ejemplo, en relación al conocimiento de los docentes sobre sus alumnos migrantes para que puedan proveer espacios de adaptación y desarrollo lingüístico frente a los demás compañeros. Asimismo, en la medida en la que se pueda cambiar uno de los factores que influye sobre el desarrollo del vocabulario del niño rural, este podrá estar más cerca de alcanzar oportunidades equitativas, en lugar de ser determinado por factores externos a sus propias habilidades. El niño debería encontrar en su medio todas las disposiciones necesarias para que desarrolle su potencial y no estar limitado por su condición socioeconómica, la cual repercute en las distintas oportunidades que el niño tendrá a lo largo de su vida.

Tomando como base la premisa de que si el contexto mejora, mejorará también el desarrollo del vocabulario, se deben tomar acciones al respecto si se considera la trascendencia de esta dimensión, no solo para logros académicos (como la comprensión lectora), sino también para el desarrollo cognitivo y social que llevará el niño a lo largo de su vida (Berko Gleason, 2010; Reátegui, 2008; Santrock, 2007), que le irá abriendo nuevas oportunidades que, a lo largo del tiempo, permitan que las nuevas generaciones alcancen un mejor desarrollo a todo nivel. 


\section{CONCLUSIONES}

Las principales conclusiones del presente estudio se resumen en los siguientes temas:

- En el contexto de la población peruana nacida en áreas rurales alrededor del año 2000, se presentan evidencias que un niño que nace y crece en áreas rurales tendrá menos probabilidades de desarrollar ampliamente su vocabulario, frente a un niño que migró a zonas urbanas, especialmente en los primeros cinco años de su vida.

- Se encuentra que los factores contextuales cobran un papel principal en el desarrollo infantil, específicamente del vocabulario, el cual tiene trascendencia tanto en aspectos académicos de la trayectoria educativa de los niños como en aspectos cognitivos que permitirán desarrollar niveles superiores de pensamiento.

- Asimismo, el rol de la madre ejerce un alto poder predictor sobre la amplitud del vocabulario. Esta, junto con el nivel socioeconómico, son variables difícilmente reversibles en la vida de un niño.

- El potencial del niño, en cuanto a su desarrollo de vocabulario, no puede estar limitado a condiciones que vienen determinadas por el hogar en el que nace. Por lo contrario, el niño debería encontrar condiciones externas que favorezcan su desarrollo y representen oportunidades educativas ante sus pares de áreas urbanas para poder desarrollar dicho potencial.

- El niño que esté rodeado de un contexto y relaciones sociales que estimulen su desarrollo cognitivo y lingüístico (ej. mayores interacciones con sus padres y maestros, mayores recursos didácticos) es aquel que tiene mayores posibilidades para ampliar su vocabulario receptivo.

- Los resultados de la investigación evidencian que la teoría ecológica de Bronfenbrenner se mantiene vigente, aún en contextos rurales del Perú en el siglo XXI. Tener en cuenta dicha teoría no solo permitirá comprender la realidad sino 
también encontrar estrategias adecuadas de intervención que involucren los diferentes sistemas contextuales que influyen sobre el niño en desarrollo.

- El presente estudio aporta evidencias para el conocimiento del desarrollo de los niños rurales y migrantes del Perú. Es decir, provee sustento para proponer iniciativas de desarrollo infantil para esta población poco estudiada; al mismo tiempo que tomar conciencia de la importancia de la gestión descentralizada de la educación. 


\section{RECOMENDACIONES}

A partir de estas conclusiones que resumen el escenario, se plantean las siguientes recomendaciones:

- Continuar con la identificación y análisis de los factores ambientales de las zonas rurales, que tienen mayor repercusión sobre el desarrollo lingüístico y cognitivo, y profundizar en dichos análisis de modo que puedan diseñarse estrategias específicas de acción a favor de una mayor estimulación cognitiva.

- Tomar conciencia de la urgencia para revertir esta situación de desigualdad explicada por la pobreza, la educación de la madre y contexto geográfico de desarrollo. Si bien son asuntos que se resuelven a largo plazo, deben tenerse en la agenda de prioridades a nivel nacional. Es fundamental la promoción de intervenciones que se ocupen no solo de las características familiares sino también de la comunidad.

- Una medida a tomar puede ser el fortalecimiento de la estimulación lingüística y cognitiva por parte de los docentes con sus alumnos, prestando especial atención a los estudiantes migrantes, buscando acortar las brechas con las que llegan los niños a la escuela por sus características familiares. Este fortalecimiento podría realizarse en el marco de algún programa educativo, ya sea una política pública o de alguna $\mathrm{ONG}$, sobre todo en zonas rurales.

- Se recomienda ampliar el estudio, analizando la variabilidad del desarrollo del vocabulario en el tiempo, incluyendo los puntajes del TVIP para esta misma muestra a los 5 años de edad y a los 12 años de edad. Así, se podría identificar con mayor precisión la fuerza de la influencia del contexto geográfico en el que crecen los niños sobre el desarrollo y mejora del vocabulario. 


\section{REFERENCIAS}

Alexander, B. y Uccelli, P. (2010). Desarrollo Semántico: El aprendizaje del significado de las palabras. En J. Berko Gleason, y N. Bernstein Ratner. (Eds.), Desarrollo del lenguaje ( $7^{a}$ edición) (pp. 128-146). Madrid: Pearson Educación.

Alfonso, C. e Ibáñez, O. (2013). Estimulación del desarrollo en la infancia: inteligencia, lenguaje, afectividad y otras áreas. Madrid: Dykinson.

American Educational Research Association [AERA], American Psychological Association [APA] y National Council on Measurement in Education [NCME]. (2014). Standards for Educational and Psychological testing. Washington: AERA.

Berko Gleason, J. (2010). El desarrollo del lenguaje: Una revisión y una vista preliminar. En J. Berko Gleason, y N. Bernstein Ratner (Eds.), Desarrollo del lenguaje ( $7^{\mathrm{a}}$ edición) (pp. 21-58). Madrid: Pearson Educación.

Bornstein, M. y Putnick, D. (2012). Cognitive and socioemotional caregiving in developing countries. Child Development 83(I), 46-61. http://10.1111/j.14678624.2011.01673.x.

Bronfenbrenner, U. (1987). La ecología del desarrollo humano: Experimentos en entornos naturales y diseñados. Barcelona: Ediciones Paidós.

Brownell, M., Ekumab, O., Nickel, N., Chartier, M., Kosevab, I. y Santos, R. (2016). A population-based analysis of factors that predict early language and cognitive development. Early Childhood Research Quarterly, 35, 6-18. http://10.1016/j.ecresq.2015.10.004

Bruner, J. (1989). Acción, pensamiento y lenguaje. Madrid: Alianza Editorial.

Coddington, C., Mistry, R. y Bailey, A. (2014). Socioeconomic status and receptive vocabulary development: Replication of the parental investment model with Chilean preschoolers and their families. Early Childhood Research Quarterly 29 (4), 538-549. http://10.1016/j.ecresq.2014.06.004

Cohen, J. (1992). A Power Primer. Psychological Bulletin, 112 (1),155-159.

Cueto, S., Escobal, J., Penny, M. y Ames, P. (2012). ¿Quién se queda atrás? Resultados iniciales del estudio Niños del Milenio Tercera ronda de encuestas en el Perú. Lima: GRADE; Niños del Milenio.

Cueto, S. y León, J. (2012). Psychometric characteristics of cognitive development and achievement instrument in Round 3 of Young Lives. Lima: Young Lives.

Cueto, S., León, J., Miranda, A., Dearden, K., Crookston, B., y Behrman, J. (2016). Does pre-school improve cognitive abilities among children with early-life stunting? A longitudinal study for Peru. International Journal of Educational Research, 75, 102-114. doi: 10.1016/j.ijer.2015.09.011 
Cueto, S., León, J. y Muñoz, I. (2014). Educational Opportunities and Learning Outcomes of Children in Peru: A Longitudinal Model. En Bourdillon, M. \& Boyden, J. (Eds.), Growing up in Poverty: Findings from Young Lives (pp. 245267). London: Palgrave Macmillan.

Dezcallar, T., Clariana, M., Cladelles, R. Badia, M. y Gotzens, C. (2014). La lectura por placer: su incidencia en el rendimiento académico, las horas de televisión y las horas de videojuegos. Ocnos, 12, 107-116. Recuperado de http://www.revista.uclm.es/index.php/ ocnos/ article/view/564

Díaz, J. (2006). Pre-school Education and Schooling Outcomes in Peru. Lima: Publicaciones Niños del Milenio, GRADE.

Dunn, L., Padilla, E., Lugo, D. y Dunn, L. (1986). Test de Vocabulario en Imágenes Peabody Adaptación Hispanoamericana. Minnesota: American Guidance Service.

Escobal, J. y Flores, E. (2009). Maternal Migration and Child Well-being in Peru. Young Lives Working Paper No. 56.

Escobal, J., Lanata, C., Madrid, S., Penny, M., Saavedra, J., Suárez, P., ... Huttly, S. (2003). Niños del Milenio Perú- Estudio internacional sobre pobreza infantil: Informe Nacional Preliminar. Recuperado de: http://www.ninosdelmilenio.org/wp-content/uploads/2012/10/IP_2003.pdf

Farrant, B., Shepherd, C., Walker, R. y Pearson, G. (2014). Early vocabulary Development of Australian Indigenous Children: Identifying Strenghts. Child Development Research, 2014, 7. http://dx.doi.org/10.1155/2014/942817.

Faul, F., Erdfelder, E., Lang, A.G. y Buchner, A. (2007). G*Power 3: A flexible statistical power analysis program for the social, behavioral, and biomedical sciences. Behavior Research Methods, 39 (2), 175-191.

Field, A. (2009). Discovering Statistics using SPSS (3º edición). Dubai: Oriental Press.

Flatts, M., Manzi, J., Polloni, M., Carrasco, M., Zambra, C. y Abarzúa, A. (2016). Aportes para la enseñanza de la lectura. Santiago de Chile: UNESCO.

Fondo Internacional de Desarrollo Agrícola [FIDA] (2013). Dar a la población rural pobre del Perú la oportunidad de salir de la pobreza. Documento FIDA. Recuperado

de http://www.ifad.org/operations/projects/regions/pl/factsheet/peru_s.pdf

Henrichs, J., Rescorla, L., Schenk, J., Schmidt, H., Jaddoe, V., Hofman, A., ... Tiemeier, H. (2011). Examining Continuity of Early Expressive Vocabulary Development: The Generation R Study. Journal of Speech, Language and Hearing Research, 54, 854-869. doi: 10.1044/1092-4388(2010/09-0255).

Hernández, M. y Habib, M. (2013). Escuela, inmigración y la figura del educador social. Revista de Educación Social 16. ISSN: 1698-9097 
Hernández, R., Fernández, C. y Baptista, P. (2014). Metodología de la investigación (6º edición). México DF: McGraw-Hill.

Instituto Nacional de Estadística e Informática [INEI]. (s.f.). Preguntas Frecuentes. Recuperado del Instituto Nacional de Estadística e Informática [INEI]: http://www.inei.gob.pe/preguntas-frecuentes/

Jelleyman, T. y Spencer, N. (2008). Residential mobility in childhood and health outcomes: a systematic review. Journal of Epidemiology and Community Health, 62 (7), 584-592.

Keith, T. (2015). Multiple Regression and Beyond: An Introduction to Multiple Regression and Structural Equation Modeling. Nueva York: Routledge. II Edición

Ley General de Educación, (2003). Ley $\mathrm{N}^{\circ}$ 28044. Recuperado de: http://www.minedu.gob.pe/p/ley_general_de_educacion_28044.pdf

Marchman, V. y Fernald, A. (2008). Speed of word recognition and vocabulary knowledge in infancy predict cognitive and language outcomes in later childhood. Developmental Science 11(3), 9-16. doi:10.1111/j.14677687.2008.00671.x.

Mastin, J. y Vogt, P. (2015). Infant engagement and early vocabulary development: a naturalistic observation study of Mozambican infants from 1;1 to 2;1. Journal of Child Language, 1-30. doi:10.1017/S0305000915000148.

Ministerio de Educación del Perú [MINEDU]. (2013). PISA 2012: Primeros Resultados. Recuperado de: http://www2.minedu.gob.pe/umc/PISA/Pisa2012/Informes_de_resultados/Infor me_PISA_2012_Peru.pdf

Ministerio de Educación del Perú [MINEDU]. (2016). Resultados de la Evaluación Censal de Estudiantes 2015. Recuperado de: http://umc.minedu.gob.pe/wpcontent/uploads/2016/03/Resultados-ECE-2015.pdf

Novick, S. (2008). Las Migraciones en América Latina. Buenos Aires: Catálogos.

Núñez Delgado, P. (2013). Los procesos de comprensión lectora. Junta de Andalucía. Recuperado - D de: http://www.juntadeandalucia.es/averroes/ cepco3/competencias/lengua/aspgene rales/Teoria_Comprensionlectora\%20_PilarNunezDelgado_.pdf

Paxson, C. y Schady, N. (2007). Cognitive Development among Young Children in Ecuador. The Journal of Human Resources, 42(1), 49-84. Recuperado de: https://www.princeton.edu/rpds/papers/Paxson_Shady_Cognitive_Development _Among_Young_Children_in_Ecuador_JHR.pdf

Perinat, A. (2007). Psicología del desarrollo: Un enfoque sistémico. Tercera Edición. Barcelona: Editorial UOC. 
Piaget, J. e Inhelder, B. (1984). Psicología del niño (12 a edición). Madrid: Ediciones Morata.

Real Academia Española [RAE]. (2014). Diccionario de la lengua española. http://dle.rae.es/

Reátegui, N. (2008). Niños rurales andinos: condiciones de aprendizaje y desarrollo cognitivo-afectivo. Lima: Foro Educativo.

Riviére, A. (1996). La teoría psicológica de Vygotski. Lima: Ediciones Salmón.

Rogoff, B. (1993). Aprendices del pensamiento: El desarrollo cognitivo en el contexto social. Barcelona: Ediciones Paidós.

Romay, J., López-Corton, A. y Gil, M. (2012). Sociedad urbana e inmigración en España: Nuevo marco de las relaciones grupales. Persona, 15, 225-237.

Rubio-Codina, M., Attanasio, O., Meghir, C., Varela, N., y Grantham-McGregor, S. (2013). The socio-economic gradient of child development. Institute for Fiscal Studies [IFS] Working Paper No. W14/11. doi: 10.1920/wp.ifs.2014.1411

Santrock, J. (2007). Desarrollo infantil (11 a edición). México DF: McGraw Hill.

Schady, N., Behrman, J., Araujo, M., Azuero, R., Bernal, R., Bravo, D.,...Vakis, R. (2014). Gradientes de riqueza en el desarrollo cognitivo durante la primera infancia en cinco países de América Latina. Documento de trabajo del Banco Interamericando del Desarrollo, IDB-WP-482.

Stata (2013). Stata User's Guide Release 13. Texas: StataPress.

Takeuchi, H., Taki, Y., Hashizume, H., Asano, K., Asano M., Sassa Y.,... Kawashima, R. (2016). Impact of reading habit on white matter structure: Cross-sectional and longitudinal analyses. NeuroImage, 133, 378-389. doi: 10.1016/j.neuroimage.2016.03.037

UNESCO (2014). Logros de aprendizaje: Perú - TERCE. Santiago de Chile: Oficina Regional de Educación para América Latina y Caribe. Recuperado de: http://umc.minedu.gob.pe/wp-content/uploads/2015/09/Peru-logrosaprendizaje.pdf

UNICEF (2006). Temas de Políticas Públicas: Migración e infancia. Panamá: Oficina Regional para América Latina y el Caribe. Recuperado de: http://www.unicef.org/lac/migracion_e_infancia.pdf

Verdisco, A., Cueto, S., Thompson, J., y Neuschmidt, O. (2015). PRIDI, Urgencia y posibilidad: Una primera iniciativa para crear datos comparables a nivel regional sobre desarrollo infantil en Latinoamérica. Banco Interamericano del Desarrollo. Recuperado de: https://publications.iadb.org/bitstream/handle/11319/6849/PRIDI.\%20Urgencia $\% 20 \mathrm{y} \% 20$ Posibilidad.pdf?sequence $=4$ 
Walker, S., Wachs, T., Gardner, J., Lozoff, B., Wasserman, G., Pollitt, E. y Carter, J. (2007). Child development: risk factors for adverse outcomes in developing countries. Lancet, 369, 145-57. doi: 10.1016/S0140-6736(07)60076-2.

Yamada, G. (2012). Patrones de migración interna en el Perú reciente. Empleo y Protección Social, 91-124, Departamento de Economía - Pontificia Universidad Católica del Perú. Recuperado de: http://departamento.pucp.edu.pe/economia/images/documentos/LDE-2012-0104.pdf 


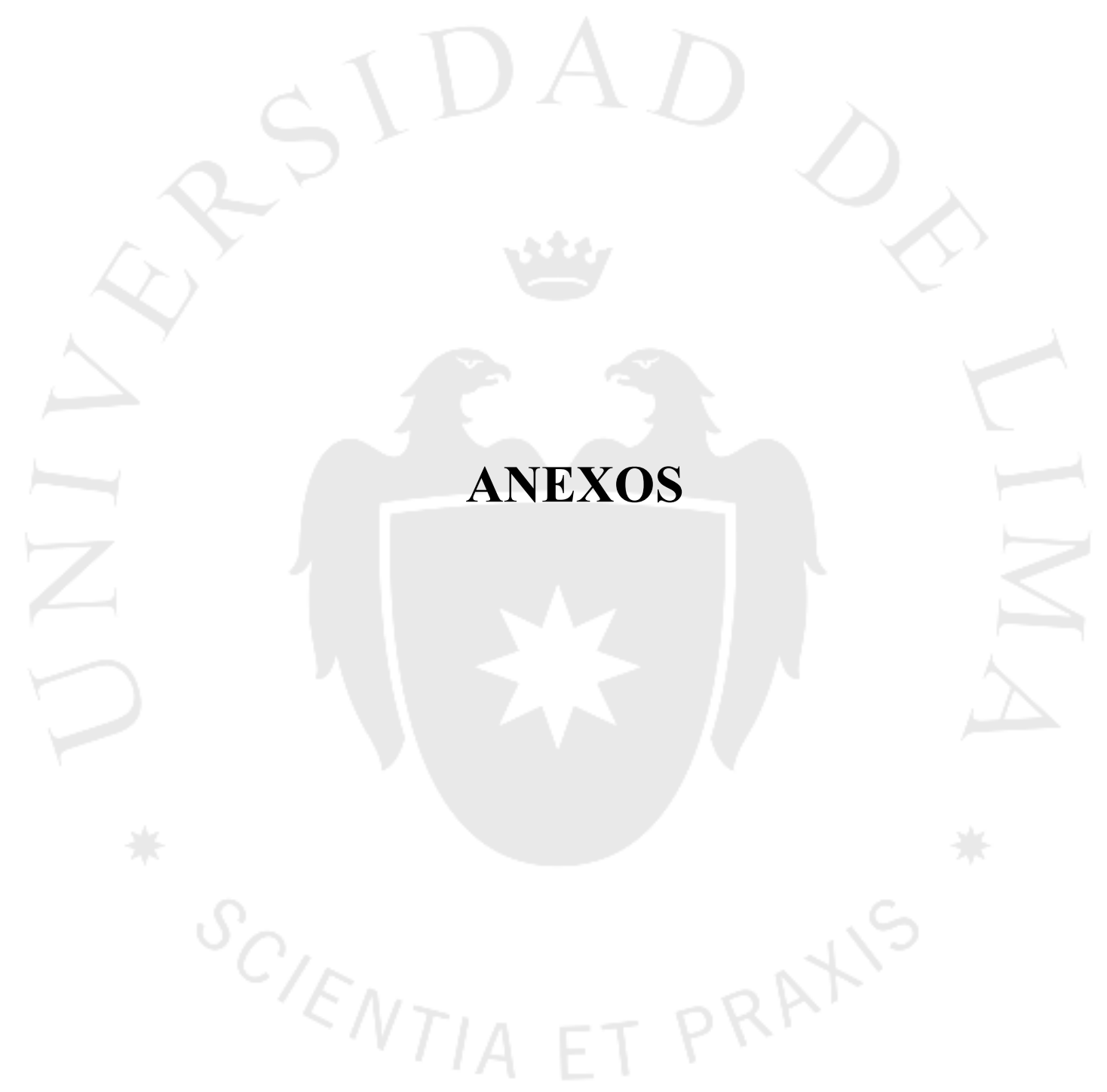




\section{ANEXO 1: Variables predictoras del desarrollo del vocabulario y teoría ecológica}

Relación de las variables predictoras utilizadas en el prpesente estudio con la teoría ecológica de Bronfenbrenner (1987)

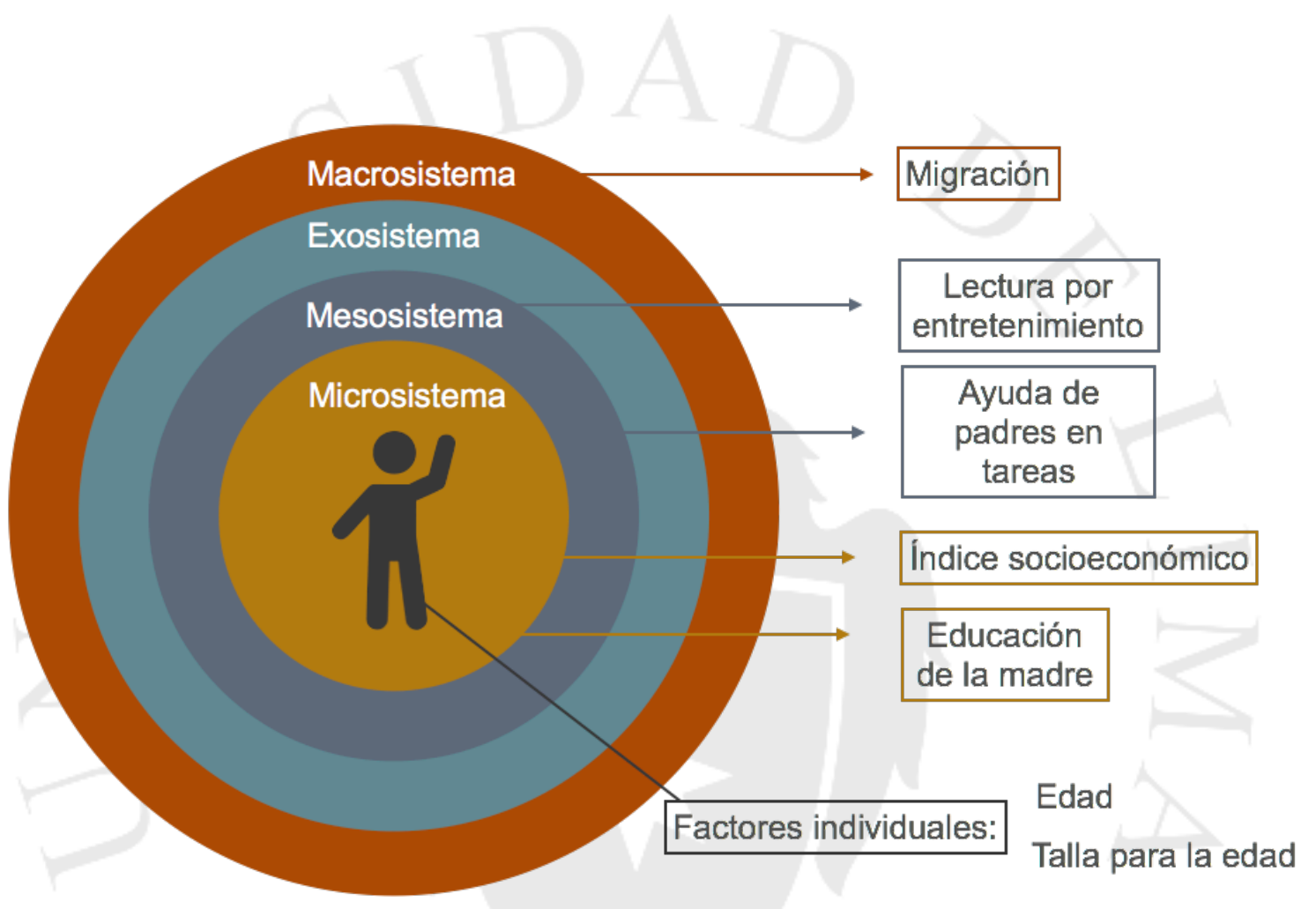

Fuente: Elaboración propia, tomando como referencia la descripción gráfica de la teoría ecológica de Bronfenbrenner (1987). 


\title{
ANEXO 2: Instrumento 1 - Hoja de Respuestas del TVIP
}

\author{
TEST DE VOCABULARIO EN IMÁGENES DE PEABODY (TVIP)
}

Encuestador: Es muy importante asegurarse de que existen condiciones adecuadas para la evaluación. Debe buscar un lugar con suficiente iluminación (natural 0 artificial), sin ruidos 0 distracciones y que tenga una superficie plana para que el niño trabaje. Si estas condiciones no están disponibles, trate de buscar otro espacio que cumpla con estas condiciones o reprograme la evaluación para otro día, si es posible.

Encuestador: Use el TVIP aquí. Asegúrese de leer al niño/niña los ítems de práctica y que el niño/niña entiende qué debe hacer antes de empezar la prueba misma. Todas las instrucciones para el TVIP están en el manual. Use los ítems A, B y $C$ (diseñados para niños menores de 8 años).

\begin{tabular}{|l|c|c|c|}
\hline \multicolumn{4}{|c|}{ DATOS DE EDAD (CONTROL DE CAMPO) } \\
\hline & Año & Mes & Día \\
\hline Fecha del examen & & & \\
\hline Fecha de nacimiento & & & \\
\hline Edad cronológica & & & \\
\hline * Si el número de días excede de 15, añada un mes a la edad
\end{tabular}

\begin{tabular}{|c|c|c|c|c|c|c|c|c|}
\hline \multicolumn{9}{|c|}{ ITEMS DE PRACTICA (CONTROL DE CAMPO) } \\
\hline \multirow[t]{2}{*}{ Lámina } & \multicolumn{2}{|c|}{ Serie 1} & \multicolumn{2}{|c|}{ Serie 2} & \multicolumn{2}{|c|}{ Serie 3} & \multicolumn{2}{|c|}{ Serie 4} \\
\hline & \multicolumn{5}{|c|}{ Para la mayoría de personas menores de 8 años } & \\
\hline$A$ & Muñeca (4) & {$[\ldots]$} & Tenedor (1) & {$[\ldots]$} & Mesa (2) & {$[\ldots]$} & Perro (3) & {$[\ldots]$} \\
\hline B & Hombre (2) & {$[\ldots]$} & Peine (3) & {$[\ldots]$} & Media (4) & {$[\ldots]$} & Boca (1) & {$[\ldots]$} \\
\hline \multirow[t]{2}{*}{$c$} & Columpiar (3) & {$[\ldots]$} & Beber (4) & {$[\ldots]$} & Andar (1) & {$[\ldots]$} & Subir (2) & {$[\ldots]$} \\
\hline & \multicolumn{5}{|c|}{ Para la mayoría de personas de 8 años a más } & & & \\
\hline$D$ & Rueda (4) & {$[\ldots]$} & Cierre (2) & {$[\ldots]$} & Soga (1) & {$[\ldots]$} & Rastrillo (3) & {$[-]$} \\
\hline$E$ & Trapear (1) & {$[-]$} & Podar (3) & {$[\ldots]$} & Aserrar (4) & {$[-]$} & Pasear (2) & {$[-]$} \\
\hline
\end{tabular}

Encuestador: Luego de administrar los ítems de práctica apropiados, empiece la prueba con el ítem que corresponda a la edad del niño/niña.

Use números (1-4) para registrar las respuestas del niño/niña a cada ítem en la columna "Rpta". La columna "Clave" indica la respuesta correcta (1-4). Compare la respuesta del niño/niña con la clave e indique si ha cometido un error cruzando una línea sobre el símbolo en la última columna como se indica a continuación:

\begin{tabular}{|c|c|c|c|c|}
\hline$\#$ & Palabra & Clave & Rpta & Error \\
\hline 1 & Barco & (2) & 3 & $\boldsymbol{b}$ \\
\hline
\end{tabular}

Al final, registre el número de errores en la celda apropiada.

ENCUESTADOR: Por favor complete las preguntas 1.2 y 1.3 luego de administrar el TVIP al niño/niña (estos ítems ayudarán en el ingreso de datos.)

\begin{tabular}{|c|c|c|}
\hline 1.2 & $\begin{array}{l}\text { Ítem más bajo respondido por el niño } \\
\text { (valores posibles: } 0 \text { a } 125, \quad-79=\text { No quiso contestar, }\end{array}$ & {$[-\ldots-]$} \\
\hline 1.3 & $\begin{array}{l}\text { Ítem más alto respondido por el niño } \\
\text { (valores posibles: } 0 \text { a } 125, \quad-79=\text { No quiso contestar, } \quad-88=N A \text { ) }\end{array}$ & {$[-\ldots-]$} \\
\hline 1.4 & Administración de la prueba: Hora de inicio (hora) (valores posibles: 00 a 23) & Horas: $[\ldots \ldots$ ] \\
\hline 1.5 & Administración de la prueba: Hora de inicio (minutos) (valores posibles: 00 a 59) & Minutos: $[\ldots \ldots]$ \\
\hline
\end{tabular}


PALABRAS DEL TEST Y CLAVE DE PUNTUACION

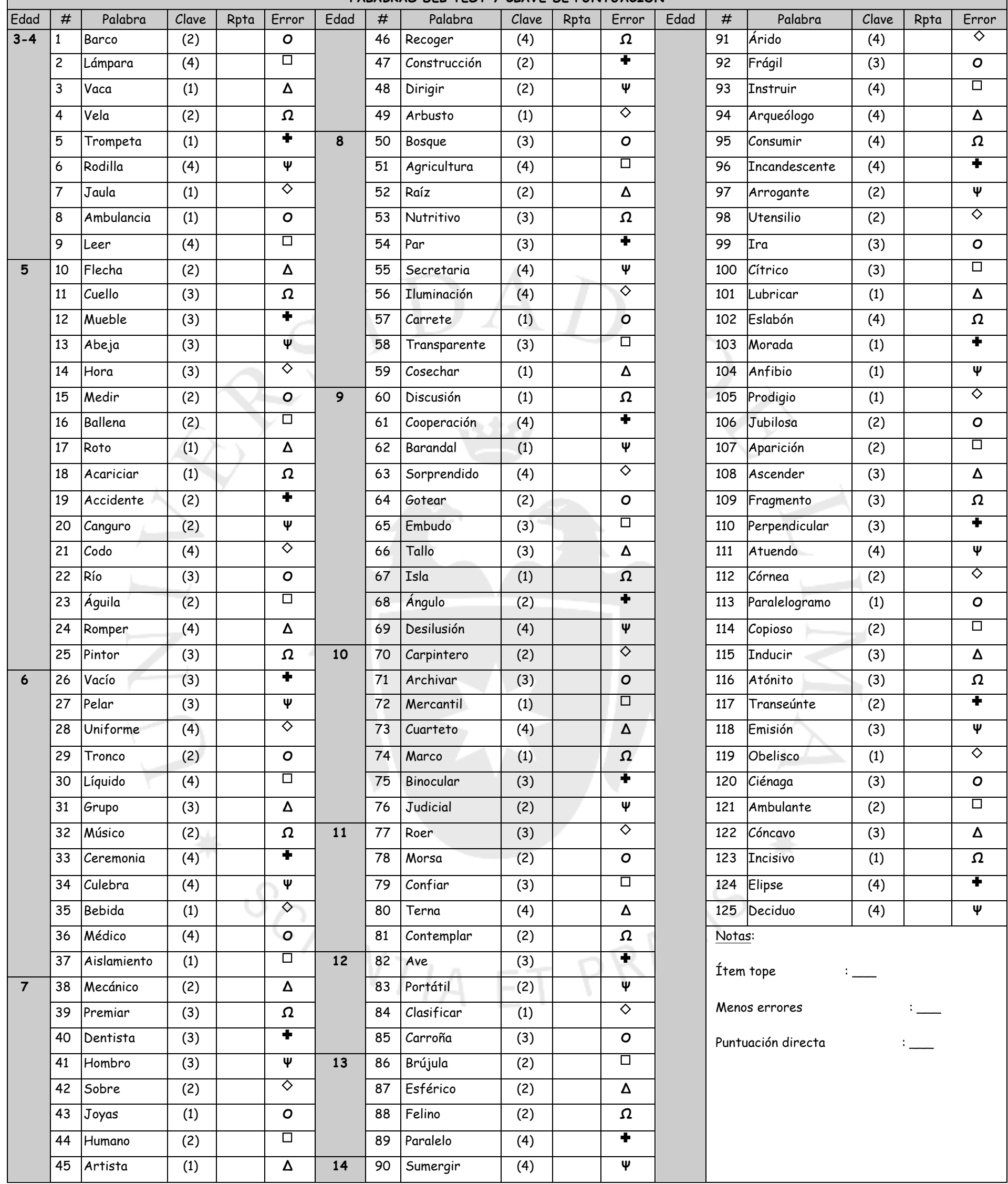

1.6 $\quad$ Administración de la prueba: Hora de fin (hora) (valores posibles: 00 a 23) $\quad$ Hora: [ _ _ ] \begin{tabular}{|lll}
\hline 1.7 & Administración de la prueba: Hora de fin (minutos) (valores posibles 00 a 59) Minutos: [ _ _ ] \\
\hline
\end{tabular} 


\section{ANEXO 3: Instrumento 2 - Preguntas del "Cuestionario del Hogar" (del Estudio Niños del Milenio) correspondientes a las variables de la presente investigación}

\begin{tabular}{|c|c|c|}
\hline $\begin{array}{c}\text { Proyecto Niños del Milenio. Instituto de Investigación } \\
\text { Nutricional, GRADE, Save the Children- UK } \\
\text { Cuestionario Niños 6-17.9 meses Perú } \\
\text { Versión Final 09 Agosto } 2002\end{array}$ & $\begin{array}{l}\text { Formato } \\
\text { No: } \text { C1 } \\
--\end{array}$ & $\begin{array}{l}\text { Código Niño } \\
\text { PE -__-1-___ _ }\end{array}$ \\
\hline
\end{tabular}

\section{Sección Enrolamiento}

DECIR: Soy trabajador(a) del Instituto de Investigación Nutricional, de Lima, y ahora estamos trabajando en el proyecto llamado "Niños del Milenio". Este proyecto trata de evaluar el desarrollo de los niños y se está llevando a cabo en forma simultánea en varios países del mundo. ¿Me permitiría Ud. hacerle algunas preguntas para ver si hay alguien en su hogar que podría ser elegido para participar en este proyecto? Si es así, le explicaré con más detalle en qué consiste el proyecto y contestaré todas las preguntas que pueda tener de modo que Ud. pueda decidir si quiere participar en este proyecto o no. Es importante que Ud. sepa que toda la información que me dé será tratada en forma estrictamente confidencial. No le daremos la información que Ud. nos otorgue a nadie y sólo será usada para análisis de todo el proyecto en su conjunto

E6 ¿Cuál es la fecha de nacimiento del niño?

E7 ¿El sexo del niño elegido es masculino o femenino $? 1=$ Masculino $2=$ Femenino

E11 Dirección de la vivienda del niño:

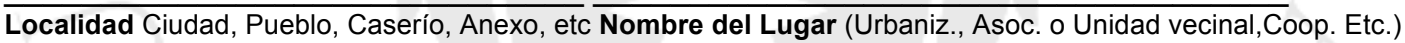

\begin{tabular}{|l|l|l|l|l|l|l|l|}
\hline Cat & $\begin{array}{l}\text { Nombre de calle, Av., Jr., } \\
\text { carretera, etc. }\end{array}$ & Número & Interior & Piso & Manzana & Lote & Km \\
\hline & & & & & & & \\
\hline
\end{tabular}

Categoría: Av=avenida, Jr= Jirón, Ca= Calle, Psje= Pasaje, Carr= Carretera,Via, S/N = sin nombre, sin número.

1 = Primer piso, vivienda de un solo piso

\section{SECCION 2: Composición del Hogar}

2.4 ¿En Total Cuántas personas viven en este hogar?

2.5.7 ¿Cuál fue el último año o grado de estudios que completó la madre o cuidador principal (dentro de qué nivel)? 
$00=$ Ninguno

01 $=$ Transición

$02=$ Está en $1^{\circ}$ Grado

03= Primaria

04 $=$ Secundaria

05= Sup. No Univ Incomp.
06= Sup. No Univ. Complet.

07= Univ. Incompleta.

$08=$ Univ.Completa

77= Otro:

$88=$ No Procede

$99=$ No Sabe

\section{SECCION 6: Información sobre antecedentes de la Madre}

6.4.2 ¿Cuál fue el idioma que su madre le habló desde cuando era niña?:
$01=$ Castellano
$05=$ Inglés
02 = Quéchua
07 = Otro Extranjero (Especifique)
03 = Aymara
08 = Otro:(especifique
04 = Nativa de la Selva
$88=$ No Procede $99=$ No Sabe

\section{SECCION 9: Estado Socio Económico}

9.2 ¿En total, cuántas habitaciones hay en esta casa? (No incluye baño, cocina, pasadizo, garaje, ni depósito)

\subsection{1 ¿Tiene energía eléctrica? 1 = Sí $2=$ No}

\subsubsection{Encuestador(a): Observe el tipo de paredes}

$1=$ Ladrillo $/$ Concreto $3=$ Madera $/$ tronco $5=$ Esteras $7=$ Piedra con barro

2 = Adobe $/$ Tierra 4 = Calamina $/$ Fierro 6 = Quincha 8 = Otro:

\subsubsection{Encuestador(a): Observe el tipo de techo}

$1=$ Paja $/$ Esteras $3=$ Madera $/$ Hojas $5=$ Concreto $/$ Cemento $7=$ Otro:

$2=$ Adobe $/$ Tierra $4=$ Calamina $/$ Fierro $6=$ Tejas $/$ Losetas

\subsubsection{Encuestador(a): Observe el tipo de piso}

$1=$ Tierra $/$ arena $3=$ Piedra $/$ ladrillos $5=$ Material laminado $/$ vinílico

$2=$ Madera 4 = Cemento $/$ losetas $6=$ Otro:

9.3 ¿Cuál es la fuente principal de agua para beber que utiliza su familia?

1 = Tubería que llega a la casa/lote/terreno $\quad 4$ = Lago/río/manantial,acequia/canal no protegido

2 = Pozo, entubado con bomba manual $\quad 5=$ Camión tanque, aguatero

3 = Caño público/fuente/pileta/pozo público $\quad 6$ = Otro(Especifique):

\section{4 ¿Qué tipo de baño usan en su hogar?}

1 = Inodoro con agua / Pozo séptico dentro de la casa

2 = Ninguno (campo, cerro, huerto, corral, etc.)

4 = Letrina pública / comunal

$3=$ Letrina dentro de la casa.

9.5 ¿Cuál es el principal tipo de combustible que usan para cocinar

$\begin{array}{ll}1=\text { Madera }, \text { leña } & 4=\text { Carbón de palo } \\ 2=\text { Ninguno } & 5=\text { Gas } / \text { electricidad } \\ 3=\text { Kerosene } / \text { parafina } & 6=\text { Carbón de piedra }\end{array}$

$7=$ Bosta de vaca

8 = Otro(especifique):

$3=$ Kerosene $/$ parafina $\quad 6=$ Carbón de piedra

99 = No Sabe 


\begin{tabular}{|l|l|l|l|}
\hline \multicolumn{3}{|l|}{ 9.7 ¿Ud. O Alguien en su casa, (hogar), tiene, es de su propiedad?: } & $\begin{array}{l}\text { 1=Si 2=No } \\
9=\text { No Sabe }\end{array}$ \\
\hline 9.71 & ¿Radio que funciona? & $\mathbf{9 . 7 1}$ & \\
\hline 9.7 .2 & ¿Refrigeradora que funciona (eléctrica/kerosene? & $\mathbf{9 . 7 . 2}$ & \\
\hline 9.7 .2 .1 & ¿Plancha que funciona? & $\mathbf{9 . 7 . 2 . 1}$ & \\
\hline 9.7 .2 .2 & ¿Licuadora / batidora que funciona? & $\mathbf{9 . 7 . 2 . 2}$ & \\
\hline 9.7 .2 .3 & ¿Cocina a gas o a electricidad, que funciona? & $\mathbf{9 . 7 . 2 . 3}$ & \\
\hline 9.7 .3 & ¿Bicicleta que funciona? & $\mathbf{9 . 7 . 3}$ & \\
\hline 9.7 .4 & ¿Televisor que funciona? & $\mathbf{9 . 7 . 4}$ & \\
\hline 9.7 .4 .1 & ¿Tocadiscos, equipo de música que funciona? & $\mathbf{9 . 7 . 4 . 1}$ & \\
\hline 9.7 .4 .2 & ¿Ventilador que funciona? & $\mathbf{9 . 7 . 4 . 2}$ & \\
\hline 9.7 .4 .3 & ¿Videocasetera que funciona? & $\mathbf{9 . 7 . 4 . 3}$ & \\
\hline 9.7 .4 .4 & ¿Lavadora de ropa que funciona? & $\mathbf{9 . 7 . 4 . 4}$ & \\
\hline 9.7 .4 .5 & ¿Secadora de ropa que funciona? & $\mathbf{9 . 7 . 4 . 5}$ & \\
\hline 9.7 .4 .6 & ¿Lustradora / aspiradora que funciona? & $\mathbf{9 . 7 . 4 . 6}$ & \\
\hline 9.7 .5 & ¿Motocicleta / motoneta / motocar que funciona? & $\mathbf{9 . 7 . 5}$ & \\
\hline 9.7 .6 & ¿Vehículo (carro, camión, taxi, etc.) que funciona? & $\mathbf{9 . 7 . 6}$ & \\
\hline 9.7 .7 & ¿Tractor que funciona? & $\mathbf{9 . 7 . 7}$ & \\
\hline 9.7 .8 & ¿Herramienta o equipo agrícola / Ganadero? & $\mathbf{9 . 7 . 8}$ & \\
\hline 9.7 .9 & ¿Teléfono celular que funciona? & $\mathbf{9 . 7 . 9}$ & \\
\hline 9.7 .10 & ¿Teléfono fijo que funciona? & $\mathbf{9 . 7 . 1 0}$ & \\
\hline 9.7 .11 & ¿Máquina de coser que funciona? & $\mathbf{9 . 7 . 1 1}$ & \\
\hline 9.7 .12 & ¿Máquina de tejer que funciona? & $\mathbf{9 . 7 . 1 2}$ & \\
\hline 9.7 .13 & ¿Terma eléctrica / a gas que funciona? & $\mathbf{9 . 7 . 1 3}$ & \\
\hline 9.7 .14 & ¿Computadora / notebook que funciona? & $\mathbf{9 . 7 . 1 4}$ & \\
\hline 9.7 .15 & ¿Horno microonda que funciona? & $\mathbf{9 . 7 . 1 5}$ & \\
\hline
\end{tabular}

\section{Sección 13. ANTROPOMETRÍA}

TALLA: 13.7 - NIÑO (9s=No se sabe/No se tomó) $\mathrm{cm}$

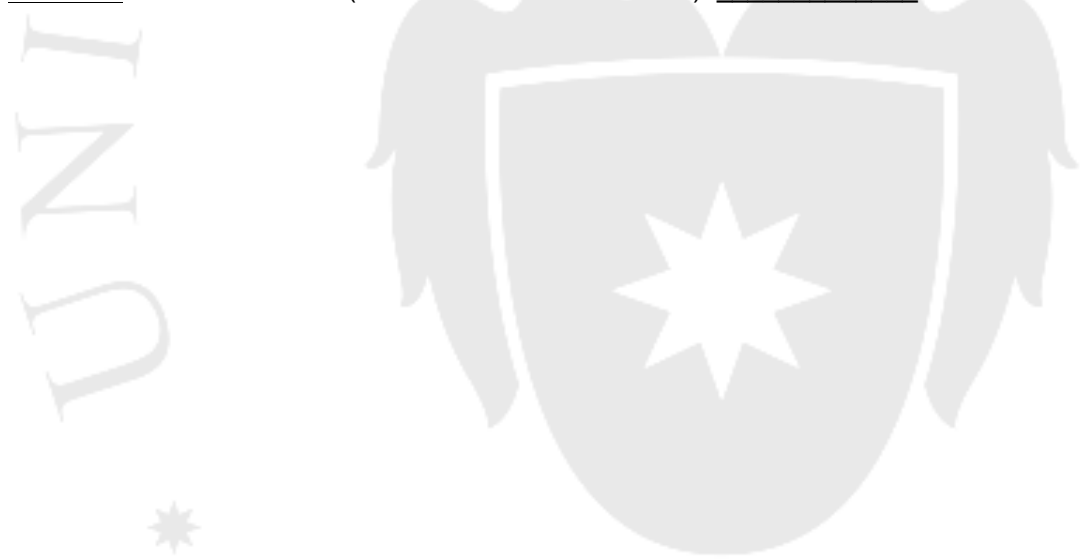




\begin{tabular}{|c|l|l|}
\hline $\begin{array}{c}\text { Proyecto Niños del Milenio. IIN, GRADE, Save the } \\
\text { Children- UK }\end{array}$ & $\begin{array}{l}\text { Formato } \\
\text { R2INDX }\end{array}$ & Código Niño \\
PE - $\begin{array}{c}\text { Cuestionario del Hogar - Perú. Niños de } 5 \text { años } \\
\text { Versión Final 06 Noviembre 2006 }\end{array}$ & & \\
\hline
\end{tabular}

Fecha de la entrevista (día/mes/año): ____

Dirección de la vivienda del niño:

Localidad Ciudad, Pueblo, Caserío, Anexo, etc Nombre del Lugar (Urbaniz., Asoc. o Unidad vecinal,Coop. Etc.)

\begin{tabular}{|l|l|l|l|l|l|l|l|}
\hline Cat & $\begin{array}{l}\text { Nombre de calle, Av., Jr., } \\
\text { carretera, etc. }\end{array}$ & Número & Interior & Piso & Manzana & Lote & Km \\
\hline & & & & & & & \\
\hline
\end{tabular}

Categoría: Av=avenida, Jr= Jirón, Ca= Calle, Psje= Pasaje, Carr= Carretera,Via, $\mathrm{S} / \mathrm{N}=$ sin nombre, sin número.

$1=$ Primer piso, vivienda de un solo piso

1.21.1 ¿Cuál fue el primer idioma que Nombre del niño aprendió en casa?

$01=$ Castellano $\quad 05=$ Inglés

$02=$ Quéchua $\quad 07=$ Otro Extranjero (Especifique)

$03=$ Aymara $\quad 08=$ Otro: $($ especifique

$04=$ Nativa de la Selva $\quad 88=$ No Procede $99=$ No Sabe

\begin{tabular}{|c||c||c||}
\hline PROYECTO NIÑOS DEL MILENIO: IIN, GRADE & Formato & Código Niño(a): \\
CUESTIONARIO DEL HOGAR - COHORTE MENOR -PERU & No: & PE $-1-1--$ \\
Versión FINAL 06 Julio 2009 & R3INDX & - \\
\hline
\end{tabular}

\section{CONFIRMAR CONSENTIMIENTO:}

Cuando la visitamos para la Entrevista Preliminar, usted nos dijo que estaba de acuerdo en que su niño(a) Nombre del Niño continúe participando en el estudio Niños del Milenio. Ahora que usted ha tenido tiempo para pensarlo, ¿podría decirme si sigue de acuerdo y está contenta de continuar siendo parte de este estudio? Recuerde: La participación es voluntaria y Ud. puede retirarse en el momento que lo desee.

Fecha de la entrevista (día/mes/año): ___ I

Dirección de la vivienda del niño:

Localidad Ciudad, Pueblo, Caserío, Anexo, etc Nombre del Lugar (Urbaniz., Asoc. o Unidad vecinal,Coop. Etc.)

\begin{tabular}{|l|l|l|l|l|l|l|l|}
\hline Cat & $\begin{array}{l}\text { Nombre de calle, Av., Jr., } \\
\text { carretera, etc. }\end{array}$ & Número & Interior & Piso & Manzana & Lote & Km \\
\hline & \multicolumn{3}{|c|}{} & & & & \\
\hline
\end{tabular}

1 = Primer piso, vivienda de un solo piso

SECCION 2A: HISTORIA EDUCATIVA DEL NIÑO(A)

2.1 Quisiera hacerle unas preguntas sobre la historia educativa de Nombre del Niño:

\begin{tabular}{|l|l|l|l|l|l|}
\hline 2.1 .1 & 2.1 .2 & 2.1 .3 & 2.1 .4 & 2.1 .5 & 2.1 .6 \\
\hline $\begin{array}{l}\text { En el año.... } \\
\text { cuando su hijo/a } \\
\text { tenía .... años }\end{array}$ & $\begin{array}{l}\text { ¿Asistió el niño } \\
\text { más de 6 } \\
\text { meses a } \\
\text { algún Centro } \\
\begin{array}{l}\text { Educativo o } \\
\text { Programa } \\
\text { de enseñanza? }\end{array}\end{array}$ & $\begin{array}{l}\text { Si asistió, ¿De } \\
\text { qué tipo era/ es } \\
\text { el Centro } \\
\text { Educativo o } \\
\begin{array}{l}\text { Programa? } \\
\text { Ver la Tabla de } \\
\text { Códigos \# 2 }\end{array}\end{array}$ & $\begin{array}{l}\text { A partir de los 5 } \\
\text { años de } \\
\text { edad, ¿Cuál fue } \\
\text { el Grado } \\
\text { que cursó? }\end{array}$ & $\begin{array}{l}\text { Nombre y/o } \\
\text { número del } \\
\text { Centro } \\
\text { Educativo }\end{array}$ & $\begin{array}{l}\text { Distrito donde } \\
\text { está/estaba } \\
\text { localizado el } \\
\text { Centro } \\
\text { Educativo }\end{array}$ \\
\hline 2009 & & & & & \\
\hline 2008 & & & & & \\
\hline 2007 & & & & & \\
\hline 2006 & & & & & \\
\hline 2005 & & & & & \\
\hline 2004 & & & & & \\
\hline 2003 & & & & & \\
\hline 2002 & & & & & \\
\hline 2001 & & & & & \\
\hline 2000 & & & & & \\
\hline
\end{tabular}




\begin{tabular}{|l|l|l|l|}
\hline \multicolumn{4}{|c|}{ TABLA DE CóDIGOS \#2 } \\
\hline 01 = Wawa-Wasi. & $\begin{array}{l}04=\text { Centro Educativo } \\
\text { Inicial (CEI) Público }\end{array}$ & $\begin{array}{l}07=\text { Institución Educativa } \\
\text { Parroquial (incluye Fe y } \\
\text { Alegría) }\end{array}$ & $77=$ NS \\
\hline $\begin{array}{l}02 \text { = Cuna o Guardería } \\
\text { Pública }\end{array}$ & $\begin{array}{l}05=\text { Centro Educativo } \\
\text { Inicial Privado }\end{array}$ & $\begin{array}{l}09=\text { Institución Educativa, } \\
\text { escuela o colegio Público }\end{array}$ & $88=$ NA \\
\hline $\begin{array}{l}03=\text { Cuna o Guardería } \\
\text { Privada }\end{array}$ & $06=$ PRONOEI & $\begin{array}{l}10=\text { Institución Educativa, } \\
\text { escuela o colegio Privado }\end{array}$ & 08=0tros (Especifique) \\
\hline
\end{tabular}

\section{SECCION 2C: EDUCACION DEL NIÑO}

2.12 ¿Quién ayuda a Nombre del Niño con su tarea escolar cuando él / ella lo necesita? (Solo una respuesta)

$01=$ Nadie

02= Padre

04= Cuidador(a)

07 $=$ Profesor Particular

03= Madre

$5=$ Hermanos Mayores

08= Otro (especifique):

2.15 Excluyendo los textos escolares ¿Cuántos libros aproximadamente tiene Ud. en su hogar?
$00=$ Ninguno
$02=6-10$ libros
04 = más de 20 libros
$01=1-5$ libros
$03=11-20$ libros
$77=\mathrm{NS}$

2.16 ¿El niño lee libros por diversión? (no considerar los que son parte de sus tareas escolares) $00=$ No $\quad 01=$ Sí $\quad 77=\mathrm{NS}$ 


\section{ANEXO 4: Licencia para el uso de datos del Estudio Niños del Milenio}

\section{End User Licence}

This Agreement is made between you and the University of Essex (also referred to as the "registrar") and the service funders in order to provide you (the "End User") with the right to use the collections provided via the UK Data Service, according to the terms below.

In this agreement:

"Data Team" means in relation to a particular data collection, the registrar, the relevant data service providers, and (to the extent that the Special Conditions and/or metadata specific to a particular data collection expressly provide) the service funders, data collection funders and/or original data creators or depositors.

"data service provider" means the persons or organisations that directly provide you with the data collections (on behalf of the service funder). The data service provider for a particular data collection is identified in the Special Conditions and/or metadata applicable to that data collection;

"service funder" means the persons or organisations that fund the data service provider as defined above. The service funder for a particular data collection is identified in the Special Conditions and/or metadata applicable to that data collection;

"data collection funder" means the persons or organisations that funded the collection and/or creation of the data collections. The data collection funder for a particular data collection is identified in the Special Conditions and/or metadata applicable to that data collection;

"original data creator or depositor" means the persons or organisations that originally collected, created or deposited the materials making up the data collections and/or who own the intellectual property rights in the data collections. The original data creator or depositor for a particular data collection is identified in the Special Conditions and/or metadata applicable to that data collection;

"registrar" means the person or organisation responsible for the system that registers End Users and issues them with End User Licences (being the University of Essex);

"Special Conditions" means any further conditions applicable to the use of one or more data collections by an End User, as notified to the End User in accordance with paragraph 5 of the End User Licence.

"metadata" means any additional or bibliographic information about one or more of the data collections, as notified to the End User from time to time. Metadata may be supplied by electronic means.

I (the "End User") agree to the following conditions of use in consideration of the data collections being made available to me through the various contributions of each member of the Data Team:

1. To use the data collections only in accordance with this End User Licence and to notify promptly the registrar and the data service provider of any breach of its terms in writing or of any infringements of the data collections of which I become aware.

2. To use and to make personal copies of any part of the data collections only for the purposes of not-for-profit research or teaching or personal educational development. To obtain 
permission prior to using part or all of the data collections for commercial purposes by contacting the registrar and/or relevant data service provider, where relevant, in order to obtain an appropriate licence from the rights holder(s) in question or their permitted licensee if one is available.

3. That this Licence does not operate to transfer any interest in intellectual property from the data collection funders, service funder(s), the data service providers, the original data creators, producers, depositors, copyright or other right holders (including without limitation the ONS or the Crown) to me. That any rights subsisting in materials derived now or in the future from the data collections which are the intellectual property of the Crown are hereby assigned (by way of assignment of present and future intellectual property) to the Crown by this Licence to the extent not already vested in the Crown. To take all steps necessary to give effect to this Clause (including by executing further written documentation).

4. That the Licence and the data collections are provided by the Data Team on an "as is" basis and without warranty or liability of any kind. Any representations or warranties given by any member of the Data Team relating to this licence, expressed or implied, are excluded to the maximum extent permitted by law.

5. To abide by any further conditions notified to me from time to time by the registrar or the relevant data service provider that may apply to the access to, or use of, specific materials within the data collections or particular data collections. Notice of further conditions under this paragraph may be given to me by electronic means, for example, by way of a pop-up window upon my ordering one or more data collections. My acceptance of the further conditions shall be required before I gain access to the data collections in question. In this Agreement such further conditions are referred to as Special Conditions.

6. To give access to the data collections, in whole or in part, or any material derived from the data collections, only to registered End Users who have entered into an End User Licence and accepted the relevant Special Conditions necessary to access and use the data collections (with the exception of data collections or material derived from data collections supplied for the stated purpose of teaching or included in publications made for the purposes set out in paragraph 2).

7. To ensure that the means of access to the data (such as passwords) are kept secure and not disclosed to a third party except by special written permission or licence obtained from the original data service provider.

8. To preserve at all times the confidentiality of information pertaining to individuals and/or households in the data collections where the information is not in the public domain. Not to use the data to attempt to obtain or derive information relating specifically to an identifiable individual or household, nor to claim to have obtained or derived such information. In addition, to preserve the confidentiality of information about, or supplied by, organisations recorded in the data collections. This includes the use or attempt to use the data collections to compromise or otherwise infringe the confidentiality of individuals, households or organisations.

9. To acknowledge, in any publication, whether printed, electronic or broadcast, based wholly or in part on the data collections, the original data creators, depositors or copyright holders, the service funders and the data service provider(s) in the form specified on the data distribution notes or in accompanying metadata received with the dataset or notified to me and without prejudice to paragraph 5 above to comply with any restrictions on my use of the data collections referred to or referenced therein or otherwise notified to me from time to time. To cite, in any publication, whether printed, electronic or broadcast, based wholly or in part on the data collections, the data collections used in the form specified on the data distribution notes or in accompanying metadata received with the dataset or notified to me. 
10. To supply the relevant data service provider with the bibliographic details of any published work based wholly or in part on the data collections.

11. That the members of the Data Team may hold and process any personal data submitted by me for validation and statistical purposes, and for the purposes of the management of the service or for any other lawful purpose notified to me and to which I have consented under this Agreement in relation to a particular data collection, and they may also pass the information on to other parties such as: (i) depositors and distributors of material contained in or accessed via the data service provider; (ii) copyright and other intellectual property rights owners whose material is held by the data service provider; as well as (iii) each member of the Data Team's organisation and (iv) my own institution or organisation, in compliance with the Data Protection Act 1998.

12. To notify the data service provider of any errors discovered in the data collections.

13. That any personal data submitted by me is accurate to the best of my knowledge, and that any changes in that personal data, including my educational or employment status, will be made known to the registrar at the earliest possible opportunity.

14. To meet any charges that may from time to time be levied by any member of the Data Team for the supply of the data collections including, where relevant, annual service fees and royalty fees.

15. At the conclusion of my research (or if earlier at any time at the request of a member of the Data Team), to offer for deposit in the data collection(s) on a suitable medium and at my own expense any new data collections which have been derived from the materials supplied or which have been created by the combination of the data supplied with other data. The deposit of the derived data collection(s) will include sufficient explanatory documentation to enable the new data collection(s) to be accessible to others.

16. I understand that breach of any of the provisions of this Agreement will lead to immediate termination of my access to all services provided by the Data Team either permanently or temporarily, at the discretion of a member of the Data Team, and may result in legal action being taken against me. I understand that where there is no breach of this Licence, it may be terminated, or its terms altered, by a member of the Data Team either after 30 days notice; or, if a service charge has been paid in advance, at the end of the period for which payment has been made, whichever is the longer. The failure to exercise or delay in exercising a right or remedy provided by this Agreement or by law does not constitute a waiver of the right or remedy or a waiver of other rights or remedies.

\section{DISCLAIMERS}

To the extent that applicable law permits:

(a) The members of the Data Team bear no legal responsibility for the accuracy or comprehensiveness of the data supplied.

(b) The members of the Data Team accept no liability for, and I will not be entitled to claim against them in respect of, any direct, indirect, consequential or incidental damages or losses arising from use of the data collections, or from the unavailability of, or break in access to, the service, for whatever reason.

(c) Whilst steps have been taken to ensure all licences, authorisation and permissions required for the granting of this Licence have been obtained, this may not have been possible in all cases, and no warranties or assurance are given in this regard. To the extent that additional licences, authorisations and permissions are required to use the 
data collections in accordance with this Licence, it is the End User's responsibility to obtain them.

(d) I agree to indemnify and shall keep indemnified each member of the Data Team against any costs, actions, claims, demands, liabilities, expenses, damages or losses (including without limitation consequential losses and loss of profit, and all interest, penalties and legal and other professional costs and expenses) arising from or in connection with any third party claim made against any member of the Data Team relating to my use of the data collections or any other activities in relation to the data where such use is in breach of this licence.

If the whole or any part of a provision of this Agreement is void, unenforceable or illegal for any reason, that provision will be severed and the remainder of the provisions of this Agreement will continue in full force and effect as if this Agreement had been executed with the invalid provision eliminated.

This Agreement may be enforced separately in relation to each data collection provided to the End User by any member of the Data Team and the End User. No other persons may enforce this Agreement under the Contract (Rights of Third Parties) Act 1999.

This Agreement (which is the entire agreement between the parties and supersedes any previous agreement between them) may be varied in writing by agreement of the relevant service funders, the registrar, and the End User (who may give its consent to such variations by electronic means). No consent from any other party is required to vary or rescind this Agreement.

This Agreement and any documents to be entered into pursuant to it shall be governed by and construed in accordance with the laws of England and Wales and each Party irrevocably submits to the exclusive jurisdiction of the courts of England and Wales over any claim or matter arising under or in connection with this Agreement and the documents entered into pursuant to it. 